\title{
Strand-specific transcriptomes of Enterohemorrhagic Escherichia coli in response to interactions with ground beef microbiota: interactions between microorganisms in raw meat
}

Wessam Galia ${ }^{1,2,3,4^{*}}$ (D), Francoise Leriche ${ }^{2,4}$, Stéphane Cruveiller ${ }^{5}$, Cindy Garnier ${ }^{1}$, Vincent Navratil ${ }^{6}$, Audrey Dubost ${ }^{7}$, Stéphanie Blanquet-Diot ${ }^{3}$ and Delphine Thevenot-Sergentet ${ }^{1,8}$

\begin{abstract}
Background: Enterohemorrhagic Escherichia coli (EHEC) are zoonotic agents associated with outbreaks worldwide. Growth of EHEC strains in ground beef could be inhibited by background microbiota that is present initially at levels greater than that of the pathogen E. coli. However, how the microbiota outcompetes the pathogenic bacteria is unknown. Our objective was to identify metabolic pathways of EHEC that were altered by natural microbiota in order to improve our understanding of the mechanisms controlling the growth and survival of EHECs in ground beef.

Results: Based on 165 metagenomics analysis, we identified the microbial community structure in our beef samples which was an essential preliminary for subtractively analyzing the gene expression of the EHEC strains. Then, we applied strand-specific RNA-seq to investigate the effects of this microbiota on the global gene expression of EHEC O26 21765 and O157 EDL933 strains by comparison with their behavior in beef meat without microbiota. In strain $\mathrm{O}_{26} \mathrm{C}_{21765}$, the expression of genes connected with nitrate metabolism and nitrite detoxification, DNA repair, iron and nickel acquisition and carbohydrate metabolism, and numerous genes involved in amino acid metabolism were down-regulated. Further, the observed repression of ftsL and murF, involved respectively in building the cytokinetic ring apparatus and in synthesizing the cytoplasmic precursor of cell wall peptidoglycan, might help to explain the microbiota's inhibitory effect on EHECs. For strain O157 EDL933, the induced expression of the genes implicated in detoxification and the general stress response and the repressed expression of the peR gene, a gene negatively associated with the virulence phenotype, might be linked to the survival and virulence of O157:H7 in ground beef with microbiota.

Conclusion: In the present study, we show how RNA-Seq coupled with a 165 metagenomics analysis can be used to identify the effects of a complex microbial community on relevant functions of an individual microbe within it. These findings add to our understanding of the behavior of EHECs in ground beef. By measuring transcriptional responses of EHEC, we could identify putative targets which may be useful to develop new strategies to limit their shedding in ground meat thus reducing the risk of human illnesses.
\end{abstract}

Keywords: RNA-Seq, EHEC, Ground beef, Natural microbiota, 165 metagenomics analysis

\footnotetext{
* Correspondence: wessam.galia@vetagro-sup.fr

'UMR 5557 Ecologie Microbienne, Research Group on Bacterial Opportunistic

Pathogens and Environment, CNRS, VetAgro Sup and Université de Lyon,

Lyon, France

2Université Clermont Auvergne, INRA, UMRF, F-15000 Aurillac, France

Full list of author information is available at the end of the article
} 


\section{Background}

Bacteria rapidly program their gene expression to survive changing environments and resist challenging conditions. Such adaptation through gene expression can radically change bacterial physiology and pathogenicity. RNAsequencing has revolutionized the study of gene expression because, in addition to quantifying transcriptional output, it allows the detection and characterization of all transcripts in a genome. This innovative, non a priori tool is rapidly becoming the method of choice for revealing new functional genes and pathways in individual microbes $[1,2]$ as well as in complex environmental communities, e.g. from the sea $[3,4]$ and the human gut $[5,6]$. However, deciphering the behavior of one population within a complex microbiota comprising related taxonomic species is a real challenge.

EHECs are food-borne zoonotic agents associated with disease outbreaks worldwide and represent a serious public health concern. They are strongly associated with severe forms of infection such as hemorrhagic colitis and, in some extreme cases, hemolytic-uremic syndrome (HUS) $[7,8]$. Human infection is typically acquired through ingestion of contaminated food (undercooked ground beef, dairy products, vegetables, etc.) and water. In 2014, 5955 confirmed cases of EHEC infection were reported in the EU. That year as in previous years, the most commonly reported EHEC serogroup was O157 (46.3\% of cases with known serogroup), followed by serogroups O26, O103, O145, O91, O146 and O111 (EFSA, Zoonosis 2014). Beef cattle are the primary reservoir of EHECs [9] which they carry in and excrete from their gastrointestinal tract. These animals stay without any symptoms of disease [10]. Cattle faeces is considered the main source of EHEC contamination of carcasses during slaughter [11].

Data from EFSA (Zoonosis, 2014) [12] show that the highest proportion of STEC-positive samples were reported from ruminant meat (goat, sheep, cattle and deer). Over the same period, STEC were reported in about $1 \%$ of cheese samples, particularly sheep and goat milk cheeses, while contamination was rare in RTE (Ready-To-Eat) food of plant origin. In France, the majority of STEC infections point to the consumption of undercooked minced meat [13]. We hypothesized that biotic and abiotic factors in meat could have an impact on the growth, physiology and virulence of EHEC strains. The meat microbiota might antagonize human pathogens by many different mechanisms, including production of compounds with antimicrobial activity as well as competition for attachment sites or nutrients $[14,15]$. To date, few data about the interaction between bovine meat microflora and EHECs are available.

The aim of this study was to develop a new RNA-seq tool for use with polymicrobial samples, among others. We identified metabolic pathways of EHEC that were altered by natural microbiota, to improve our understanding of the mechanisms controlling the growth and survival of EHECs in ground beef. We first conducted a $16 \mathrm{~S}$ metagenomics analysis to identify the natural microbiota present in some ground meat. We then used strand-specific RNA-seq to investigate the effects of the ground beef background microbiota on the overall gene expression of EHEC strains O2621765 and O157EDL933 by comparison with their behavior in beef meat without microbiota.

\section{Methods}

\section{Bacterial strains}

The EHECs used in this study were 0157:H7 strain EDL933 (O157 EDL933) and O26:H11 strain 21,765 (O26 21765$)$, isolated from Michigan ground beef and human fecal samples respectively and linked to human EHEC infections [16, 17].

\section{Sample preparation}

A single beef piece of about $11 \mathrm{~kg}$ taken from a local slaughterhouse was kept $72 \mathrm{~h}$ at $4{ }^{\circ} \mathrm{C}$ before processing in our laboratory. The outer part of the muscle was aseptically separated from the inner part, considering the first to be highly contaminated and the second to be devoid of bacteria. Each part was aseptically minced and divided into 4 portions of $200 \mathrm{~g}$ before homogenization in a sterile stomacher bag (Spiral Biotech, Bethesda, Md.). For each trial, the ground beef was checked for the absence of $E$. coli O26:- and O157:- [18].

Frozen cultures of EHEC were revived on plate-count agar (PCA, BioMérieux, Marcy l'Etoile, France) by incubation at $37{ }^{\circ} \mathrm{C}$ for $24 \mathrm{~h}$. One colony of each strain was selected and cultured in BHI (Brain Heart Infusion) overnight at $37{ }^{\circ} \mathrm{C}$ without agitation. Cells were harvested by centrifugation at $4000 \times \mathrm{g}$ for $15 \mathrm{~min}$ at $12{ }^{\circ} \mathrm{C}$. Pellets were suspended in $0.1 \%$ peptone (Oxoid) water $\left(12{ }^{\circ} \mathrm{C}\right)$.

The ground beef was then inoculated as follows: each $200 \mathrm{~g}$ portion was inoculated with $20 \mathrm{ml}\left(10^{8} \mathrm{CFU} / \mathrm{ml}\right)$ of EHEC strains O157 ${ }_{\text {EDL933 }}$ or $\mathrm{O} 26_{21765}$ to obtain a final concentration of about $10^{7} \mathrm{CFU} / \mathrm{g}$. For the control experiment, a similar amount of sterile peptone water was added. Each ground beef sample was hand mixed to distribute the inoculum evenly. Samples were then incubated in a sterile stomacher bag without agitation at $12{ }^{\circ} \mathrm{C}$ for 7 days. This temperature $\left(12{ }^{\circ} \mathrm{C}\right)$ was chosen as being sufficient for identifying inter-organism interactions without halting EHEC growth [19]. Three biological replicates were performed for each condition.

\section{Ground beef microbiota and EHEC enumeration}

After serial dilutions of the samples stomached $1 \mathrm{~min}$ in BPW (Buffered Peptone Water, bioMerieux, Marcy l'Etoile, France), decimal dilutions of the samples were plated and incubated in appropriate conditions: for aerobic bacteria, 
soy agar plates were incubated at $37^{\circ} \mathrm{C}$ for $24 \mathrm{~h}$; for LAB, MRS (deMan Rogosa Sharpe; Difco) agar plates were incubated in a GasPak jar (BBL, Becton Dickinson Microbiology Systems) at $30^{\circ} \mathrm{C}$ for $48 \mathrm{~h}$, complemented with a gas generating sachet (BD GasPak EZ Gas Generating Sachet). For enumeration of O157 EDL933 and $\mathrm{O}_{26} 6_{21765}$ strains, dilutions were spread respectively onto ChromID O157:H7 agar (ChromID O157:H7 + 0.05 mg/l cefixime $+2.5 \mathrm{mg} / \mathrm{l}$ tellurite, bioMérieux) and chromogen agar E. coli Brillance. The plates were incubated at $37{ }^{\circ} \mathrm{C}$ for $24 \mathrm{~h}$. All counts were performed in duplicate.

\section{Collection of EHEC cells and ground beef microbiota for metagenomic and transcriptomic analysis}

Beef samples were diluted (1:4 w/v) in cold BPW containing $0.1 \%(v / v)$ Tween X-20 and pummeled for 1 min using a stomacher lab blender (Seward Medical, London, UK). Following pummeling, the filtered samples were clarified by centrifugation at $200 \mathrm{~g}$ for $5 \mathrm{~min}$ at $4{ }^{\circ} \mathrm{C}$. The supernatants were removed to fresh tubes, and cells were collected by centrifugation at $3500 \mathrm{~g}$ for $10 \mathrm{~min}$ at $4{ }^{\circ} \mathrm{C}$.

\section{Metagenomic analysis}

Genomic DNA extraction, PCR amplification and amplicon sequencing

DNA was extracted from samples using a Genomic DNA kit (NucleoSpin Tissue, Germany). To minimize PCR bias, DNA extracts from the triplicate samples were pooled and used as the template DNA. DNA purity (A260/A280 and A260/A230) and quantity were measured with a NanoDrop ND-1000 spectrophotometer (Thermo Scientific). The V1$\mathrm{V} 3$ region of the $16 \mathrm{~S}$ rRNA gene was amplified by PCR using the primers 27F (5'-AGAGTTTGATYMTGGCT CAG-3') and 519R (5'-GWATTACCGCGGCKGCTG-3') [20]. The libraries were prepared with Nextera XT version 3 chemistry (Illumina) and the Illumina MiSeq platform sequencer produced 300 bp paired-end reads.

\section{Quality trimming, taxonomic assignments, and operational taxonomic unit clustering}

The paired-end sequences were assembled into a single sequence, ca. 510-bp. The sequences were trimmed using MOTHUR software [21] to remove primers, long homo-polymers and sequences shorter than 100 bases (Fig. 1). Reads with ambiguous bases were removed from the data set. Sequence alignment, chimeras checking, distance calculation, OTU (Operational Taxonomic Unit) clustering and selection of non-redundant sequences were performed using MOTHUR version 1.34.4 [21]. The SILVA reference file for bacteria [22] was used to align the sequences. Indeed, to assign our sequence reads to the prokaryotic taxonomy, the Naïve Bayesian Classifier tool hosted by Ribosomal Database Project (RDP Classifier) [23] and described by Wang et al. (2007) was used [24]. This method runs a bootstrapping algorithm to find the confidence limit of the assignment of each query. A bootstrap cutoff value of 0.6 was used in our study. The percentage of each bacterial genus or phylum was calculated individually for each sample, providing information on relative abundance within the individual samples based on the relative numbers of reads in each one. Sequencing reads are available at the European Nucleotide Archive under study number PRJEB13580 (ERS1119543-ERS1119545).

\section{RNA sequencing analysis}

\section{RNA extraction and DNase treatment}

Briefly, cell pellets were re-suspended in $10 \mathrm{~mL}$ of TRIzol Reagent (Ambion) and incubated for $5 \mathrm{~min}$ at $20^{\circ} \mathrm{C}$. One volume of chloroform was added to 5 volumes of homogenate; nucleic acids were then separated from proteins by centrifugation at $12,000 \mathrm{~g}$ for $15 \mathrm{~min}$ at $4{ }^{\circ} \mathrm{C}$. One volume of the aqueous supernatant was mixed with 1 volume of ethanol $70 \%$. RNA extractions were then performed according to the Qiagen recommendations, including on-column RNA purification (RNeasy Midi Kit, QIAGEN).

\section{DNase treatment}

The TURBO DNA-free kit (Ambion) was used for the DNase treatment. Total RNA was treated using a rigorous protocol that includes a double quantity of DNase (6 units). Reactions were terminated with the addition of the DNase inactivation reagent $(0.2 \times$ the reaction volume $)$ according to the kit instructions. The presence of DNA contamination was assessed by real time PCR targeting of the eae gene [25]. RNA integrity (RIN) values [26] were determined by running $1 \mu \mathrm{l}$ aliquots on a Bioanalyzer 2100 (Agilent, Technologies, Inc.) resulting in clear patterns with prominent $16 \mathrm{~S}$ and $23 \mathrm{~S}$ ribosomal bands and RIN values of $\geq 8$.

\section{RNA-Seq library preparation and sequencing}

Library construction and sequencing were performed at the MGX-Montpellier GenomiX platform. Ribo-Zero rRNA Removal Kit Bacteria (Illumina, San Diego, CA) was used to remove ribosomal RNA from $2 \mu \mathrm{g}$ of total RNA. For each sample, 100 ng mRNA-enriched fraction was used to construct sequencing libraries using Illumina's TruSeq Stranded mRNA Sample Prep Kit (Low throughput). The mRNAs were fragmented into small pieces using divalent cations under elevated temperature. The cleaved RNA fragments were copied into first strand cDNA using SuperScript II reverse transcriptase, Actinomycin D and random hexamer primers. The addition of Actinomycin D prevents spurious DNA-dependent synthesis, while allowing RNA-dependent synthesis, improving strand specificity. The second strand cDNA was synthesized by replacing dTTP with dUTP. The incorporation of dUTP quenches the second strand during amplification, ensuring that only the first cDNA strand is 


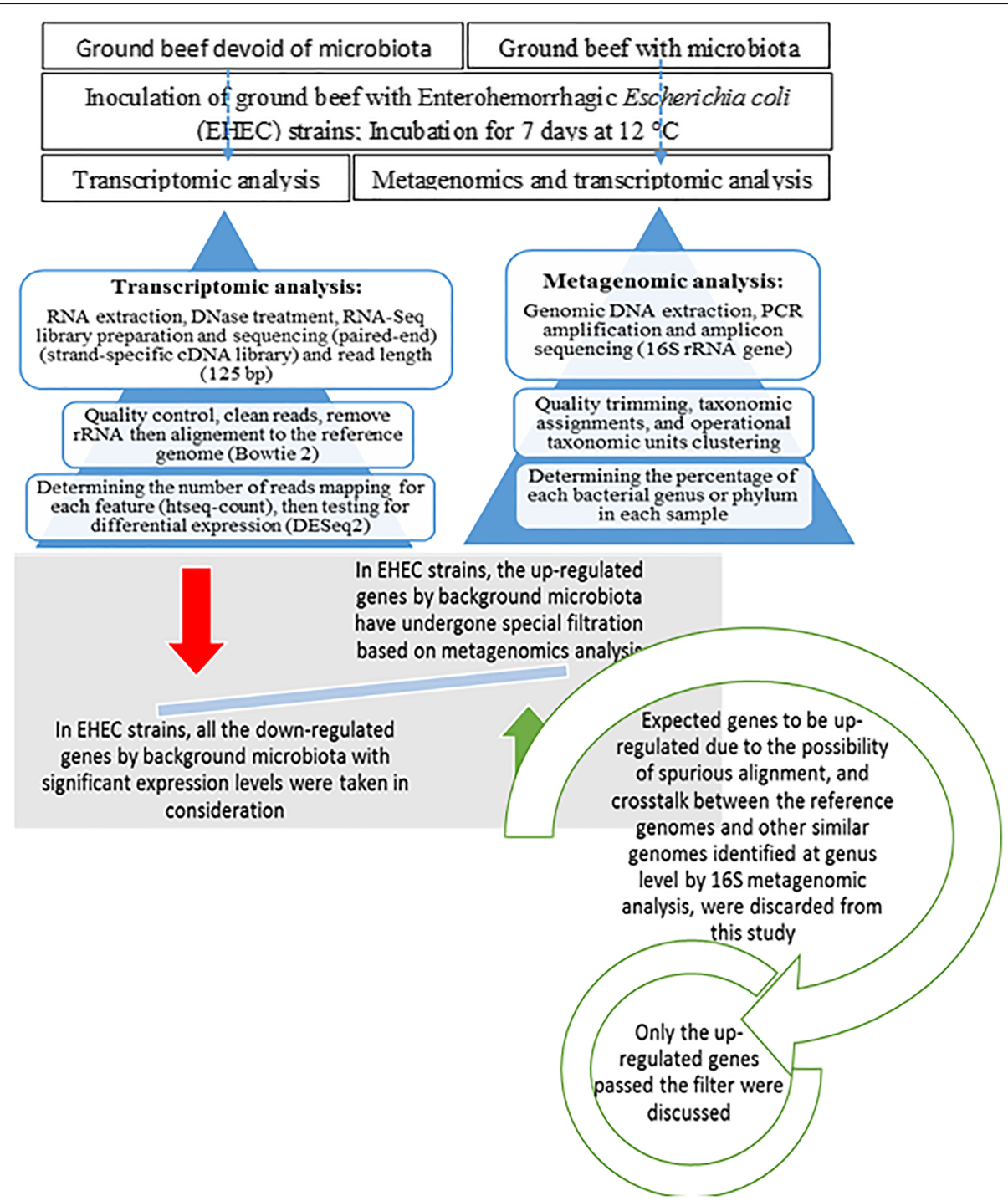

Fig. 1 Workflow for studying the overall gene expression of Enterohemorrhagic Escherichia coli (EHEC) strains O157:H7 EDL933, O26:H11 21,765 in ground meat with or without background microbiota

efficiently amplified [27, 28]. These cDNA fragments then had the addition of a single 'A' base and subsequent ligation of the adapter. The products were then purified and enriched with 15 cycles of PCR. The final cDNA libraries were validated with a DNA 1000 Labchip on a Bioanalyzer (Agilent) and quantified with a KAPA qPCR kit. For each sequencing lane of a flowcell $\mathrm{V} 4$, three to six libraries were pooled in equal proportions, denatured with $\mathrm{NaOH}$ and diluted to $7.5 \mathrm{pM}$ or $8 \mathrm{pM}$ before clustering. Cluster formation, primer hybridization and pair end-read 125 cycles sequencing were performed on cBot and HiSeq2500 (Illumina, San Diego, CA) respectively. Sequencing reads are available at the European Nucleotide Archive under study number PRJEB13600 (ERS1127228-ERS1127233; ERS1127235-ERS1127239; ERS1138027).

\section{RNA-Seq data processing}

The raw reads of RNA-seq data were processed using the galaxy.prabi.fr web service and the computing facilities of the LBBE/PRABI (Fig. 1) [29-31]. To clean the sequences, the adapters that were ligated to the $5^{\prime}$ or $3^{\prime}$ end with a maximum allowed error rate of 0.1 and a minimum overlap length of $3 \mathrm{bp}$ were removed using Cutadapt (version 1.6) [32]. Low quality sequences were then removed using Trimmomatic (version 0.32.1) [33] with the following explicit parameters: paired-end data: the minimum quality required to keep a base was 20 and the reads were trimmed when the average quality over a 4 bp window dropped below 22, starting from the $5^{\prime}$ end of the read. Moreover, trimmed/clipped sequences were kept only if they were at least $30 \mathrm{bp}$ long. The reads were then aligned and assigned 
to the reference genome using the Bowtie 2 package (version 0.2) [34], with the following parameters: paired-end alignment modes with a maximum fragment length for valid paired-end alignments of $500 \mathrm{bp}$, and end-to-end read alignment. We then used the mapped files to run HTSeq-count (version 0.4.1) [35]. This script takes an alignment file in BAM format and a feature file in GFF format and calculates the number of reads mapping to each feature. The pairedend strand-specific RNA-Seq reads were assigned to these features based on their overlapping genomic coordinates and strand orientation. Reads with more than one reported alignment were not counted for any feature. Where the reads overlapped more than one feature, the intersection-nonempty mode was used. Counts of RNA-Seq fragments were computed for each coding DNA sequence (CDS) according to the genome annotations provided by the MicroScope platform (https://www.genoscope.cns.fr/agc/microscope/) (E. coli O26:H11 21,765: chromosome ECO26H.gff, plasmid ECO26H_p.gff; E. coli O157:H7 EDL933: chromosome NC_002655.gff, plasmid AF074613.gff) $[16,36]$. Then the count tables generated by the HTSeq count were used as input to run DESeq2 (version 2.1.6.0) [37]. This tests for differential expression based on a model using the negative binomial distribution. The DESeq2 package provides its own normalization approach. The read count $K_{i j}$ for gene $i$ in sample $j$ is described with a generalized linear model (GLM). DESeq2 models read counts Kij with mean $\mu_{\mathrm{ij}}$ and dispersion $\alpha_{\mathrm{i}}$. The mean is taken as a quantity $\mathrm{q}_{\mathrm{ij}}$, proportional to the concentration of cDNA fragments from the gene in the sample, scaled by a correction factor $\mathrm{s}_{\mathrm{i} \text {. }}$. To estimate these factors, the DESeq2 package uses the median-of-ratios method [38]. The principal idea is that non differential expression (DE) genes should have similar read counts across samples, leading to a ratio of 1 . Supposing most genes are not $\mathrm{DE}$, the median of this ratio for the sample provides an estimate of the normalization factor that should be accounted for differences in sequencing depth between samples. This method is advantageous to calculate gene-specific normalization factors $\mathrm{s}_{\mathrm{ij}}$ to account for further sources of technical biases such as differing dependence on GC content or gene length. The False Discovery Rate (FDR) was controlled by adjusting $p$ values with the Benjamini Hochberg method [39]. In this report, only genes showing $\mathrm{a} \geq 2$ fold up-regulation or down-regulation with a minimum normalized read count $=10$ and a Benjamini-Hochberg FDR adjusted $p$ value of $\leq 0.005$ were considered to be differentially regulated. The transcript lists resulting from DESeq2 were then analyzed using the MicroScope platform, a webbased framework for functional analysis of large numbers of genes [40].

\section{Results and discussion}

Microbial community structures in raw ground beef inoculated or not with strains $\mathrm{O26}_{21765}$ or $0157_{\mathrm{EDL933}}$

Our experiment was designed so that EHEC strains would have sufficient time to adapt to the beef environment and that we could retrieve sufficient RNA(s) for analysis. A large initial EHEC inoculum (3 log greater than the natural microbiota counts) was chosen to ensure that the meat microbiota, present at an initial level of about $10^{4} \mathrm{CFU} / \mathrm{g}$, would not impair the growth of either O157 $7_{\text {EDL933 }}$ or $\mathrm{O}_{26} 6_{21765}$ [19]. As expected, after 7 days of incubation, no flora were detected in the inner part of the muscle, used as control, whereas in the outer part about $8 \log$ CFU/g of each type of bacteria (aerobic and LAB) were counted (Additional file 1: Table S1). In the non-inoculated ground meat samples (outer part of the muscle) commensal $E$. coli counts were about 3 logs below the level of the other natural microbiota species. In artificially contaminated minced meat obtained from the outer part, after 7 days' incubation at $12{ }^{\circ} \mathrm{C}$ the commensal E. coli were no longer detectable. They had probably lost out in competition with the two EHEC strains $\left(\mathrm{O} 157_{\text {EDL933 }}\right.$ and $\left.\mathrm{O}_{26} 6_{21765}\right)$ inoculated at an initial level of about $10^{7} \mathrm{CFU} / \mathrm{g}$. The counts of both these EHEC strains were $1 \log$ higher than the natural microbiota counts. The presence of the meat microbiota at an initial level of about $10^{4} \mathrm{CFU} / \mathrm{g}$ did not impair the growth of either O157 ${ }_{\text {EDL933 }}$ or $\mathrm{O}_{26} 6_{21765}$ (See Additional file 2: Table S2).

Using $16 \mathrm{~S}$ metagenomics analysis enabled us to characterize the bacterial populations of our samples and evaluate their relative abundances after 7 days of incubation at $12{ }^{\circ} \mathrm{C}$. A total of $2,852,952$ bacterial $16 \mathrm{~S}$ ribosomal RNA sequences, obtained from 3 samples (ground beef with natural microbiota and ground beef inoculated with strain $\mathrm{O}_{21} 6_{2165}$ or strain O157 EDL933) were analyzed. At the genus level, 2,827,664 sequences were classified (bootstrap value cutoff $=0.6$ ). However, $0.9 \%$ of total sequences were either unclassified or classified at a higher taxonomic level. In the natural microbiota of the ground beef samples, our data clearly showed that Serratia dominated (79.4\% incidence). Sequences belonging to the genus Carnobacterium and the enteric bacteria cluster amounted to $8.8 \%$ and $6.8 \%$ respectively. Carnobacterium is a psychrotrophic bacterium frequently isolated from foods, including meat [41]. Sequences from Kurthia and other bacteria were represented in smaller proportions in the control samples. In experimentally contaminated samples, Escherichia dominated the microbiota $\left(74.9 \%\right.$ for $\mathrm{O}_{2} 6_{21765}$ and $76.4 \%$ for O157 EDL933) and outnumbered Serratia, whose sequences were detected in less than 5\% (Fig. 2; Additional file 3: Table S3). The number of sequences belonging to the genus Carnobacterium was not affected by the EHEC strains. 


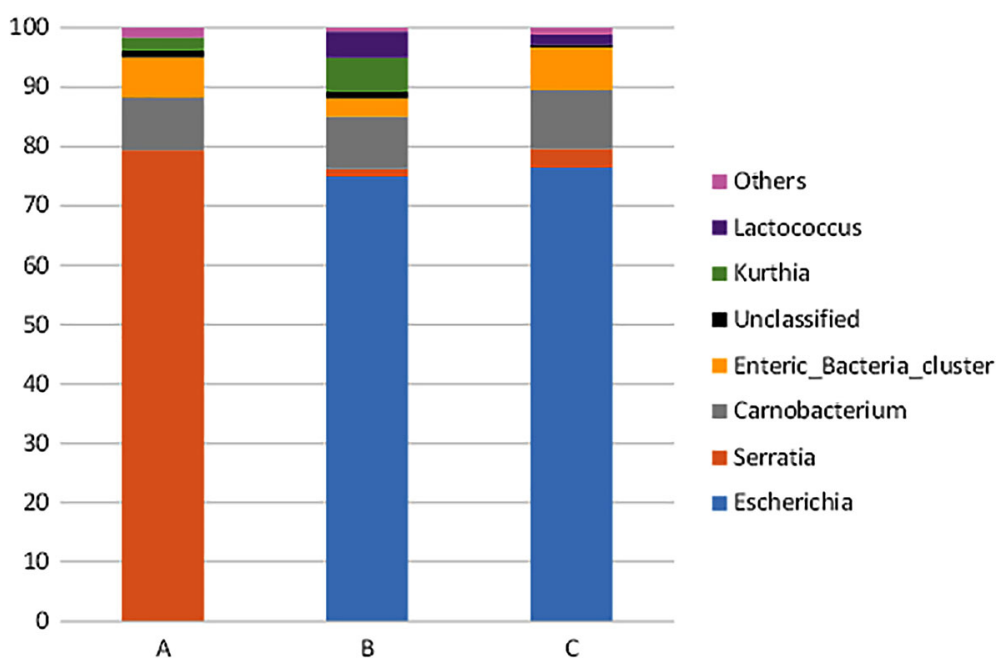

Fig. 2 Genus level distribution of sequences based on the 16S rRNA gene libraries constructed from a ground beef sample with natural microflora (a) and ground beef samples inoculated with E. coli O26:H11 21,765 (b) or E. coli O157:H7 EDL933 (c) strains. Only taxa with a percentages above 1\% are displayed in the histograms

The analysis of the microbial composition of our samples is not discussed any further in this study. For our purpose, identification of the microbial community structure at the genus level was an essential preliminary for subtractively analyzing the gene expression of the EHEC strains. It was required to identify the genes of EHEC strains expected to be differentially expressed due to the possibility of spurious alignment and crosstalk between the EHEC genes and any other similar gene identified as being part of genome sequencing data provided by GenBank and corresponding to the most abundant genus identified by $16 \mathrm{~S}$ metagenomics analysis (Fig. 1).

\section{Global gene expression of EHEC strains $\mathrm{O26}_{21765}$ and} $0157_{\text {EDL933 }}$ in ground meat with or without background microbiota

We set out to investigate the effects of ground beef background microbiota on the overall gene expression of EHEC strains $\mathrm{O}_{26} 6_{21765}$ and $\mathrm{O} 157_{\mathrm{EDL} 933}$, by comparison with their behavior in beef without microbiota. Even if eukaryotic rRNA acquired from bovine tissue cells could not be depleted owing to partial degradation, we were able to detect differential expression of numerous genes with high statistical significance thanks to the biological replicates and robust bacterial rRNA depletion. Bacterial rRNA depletion was nearly complete in all samples, since fewer than $2.3 \%$ of all high quality reads were aligned with bacterial rRNA-encoding genes (See Additional file 4: Table S4). Haas et al. (2012) has also claimed that changes in gene expression could be analyzed by RNA-Seq data analysis when the number of fragments per sample is reduced to 2-3 million [42].
Sequencing depths of $3.8 \pm 1.5$ and $4.3 \pm 2.1$ million gene mapped fragments were obtained in the $\mathrm{O}_{21765}$ and O157 EDL933 $_{2}$ datasets respectively (Additional file 4: Table S4). Based on mean normalized counts of genemapped fragments, the numbers of ORFs with at least 10 fragments that DESeq2 detected were 5035 for O157 EDL933 and 4865 for $\mathrm{O}_{26} 6_{21765}$, amounting to $88.1 \%$ and $86.7 \%$ of their annotated genes respectively.

Analysis of gene expression with significant expression levels $\geq 2$-fold and adjusted $P$-value $\leq 0.005$ revealed that the majority of genes did not differ significantly between conditions. Strain $\mathrm{O}_{26} 6_{21765}$ had a large number of significantly changed genes than O157 EDL933. Overall, of 5611 coding sequences of strain $\mathrm{O} 26_{21765}, 95$ were expressed at significantly lower levels in samples with microbiota compared to those without microbiota, and 28 were significantly up-regulated (Fig. 3; Tables 1 and 3; Additional file 5: Table S5 and Additional file 6: Table S6). The corresponding numbers for down- and up-regulated genes in strain O157 EDL933 were 21 and 25 respectively (Fig. 4; Tables 2 and 4; Additional file 7: Table S7 and Additional file 8: Table S8).

\section{Genes significantly down-regulated in ground beef with microbiota}

Genes involved in amino acid transport and biosynthesis For $\mathrm{O}_{26} 6_{21765}, 31$ of the 97 genes known, in E. coli, to encode the enzymes needed for amino acid biosynthesis [43] were down-regulated in ground meat with microbiota (Fig. 3; Table 1). For example, genes implicated in tryptophan biosynthesis $(\operatorname{trp} E, \operatorname{trp} D, \operatorname{trp} C, \operatorname{trp} B$ and $\operatorname{trp} A$ ), methionine biosynthesis, transport or regulation 


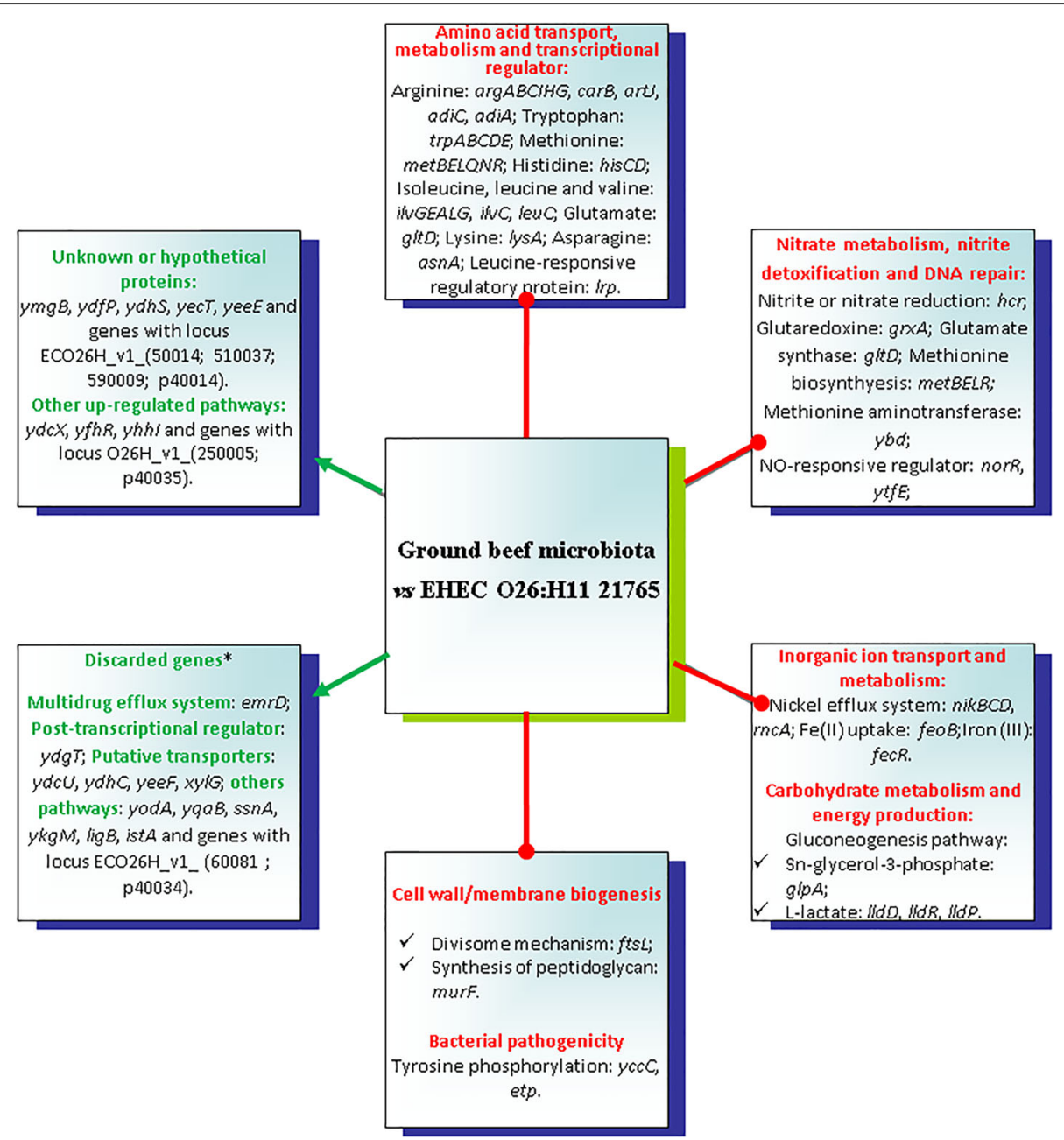

Fig. 3 Summary of the main pathways and regulations affected by background microbiota in Enterohemorrhagic Escherichia coli O26:H11 strain 21,765 in ground beef. Green arrows with head indicate up-regulation and red arrows without head down-regulation. * Genes expected to be up-regulated owing to the possibility of spurious alignment and crosstalk between the reference genome and other similar genomes identified at genus level by 165 meta-genomic analysis, were discarded from the study (For discarded genes see Additional file 6: Table S6)

(metBELQNR), biosynthesis of glutamate ( $g l t D)$, lysine $($ lys $A$ ), and arginine ( $\arg A B C I H G$ and $\operatorname{car} B$ ) and genes which encode the enzymes of the isoleucine and valine synthesis pathway (ilvGEALG) were down-regulated. For O157 EDL933, eight genes implicated in the arginine biosynthesis pathway were down-regulated (argABCEIHG and carA) (Table 2). The artI gene encoding arginine transporter subunit and the hisM gene encoding histidine/ lysine/arginine/ornithine transporter subunit were also down-regulated. The his $C D$ and hisG genes of the histidine biosynthetic pathway were down-regulated in strains $\mathrm{O}_{21} 6_{2165}$ and O157 EDL933 respectively. The $i l v C$ and artJ genes, which encode Ketol-acid reductoisomerase and arginine transporter subunit respectively, were downregulated in both strains. The $a d i C$ and adiA genes were also both down-regulated in $\mathrm{O} 26_{21765}$. Arginine produced or imported into the cell by AdiC is decarboxylated inside the cell by AdiA to form agmatine, releasing $\mathrm{CO}_{2}$ and replacing it with a proton. The $\operatorname{leu} C$ and $a s n A$ genes, which encode 3-isopropylmalate dehydratase and asparagine synthetase A respectively, were also down-regulated in $\mathrm{O} 26_{21765}$. The $l r p$ gene encoding leucine-responsive regulatory protein (Lrp) which is a global regulator of $E$. coli metabolism was down-regulated in $\mathrm{O}_{21765}$. The repression of this regulatory gene correlated well with the reduced transcript levels of its target genes, notably the decreased expression of several genes of the amino acid biosynthesis pathways (Table 1). Expression of the lrp gene is known to be regulated in part by the nutrients available to the cell, and is decreased in glucose minimal media enriched with amino acids [44]. The repression of genes involved in amino acid biosynthesis can be explained by the repression of $l r p$ in ground meat with microbiota. The hypothesis proposed is that the hydrolyzed 


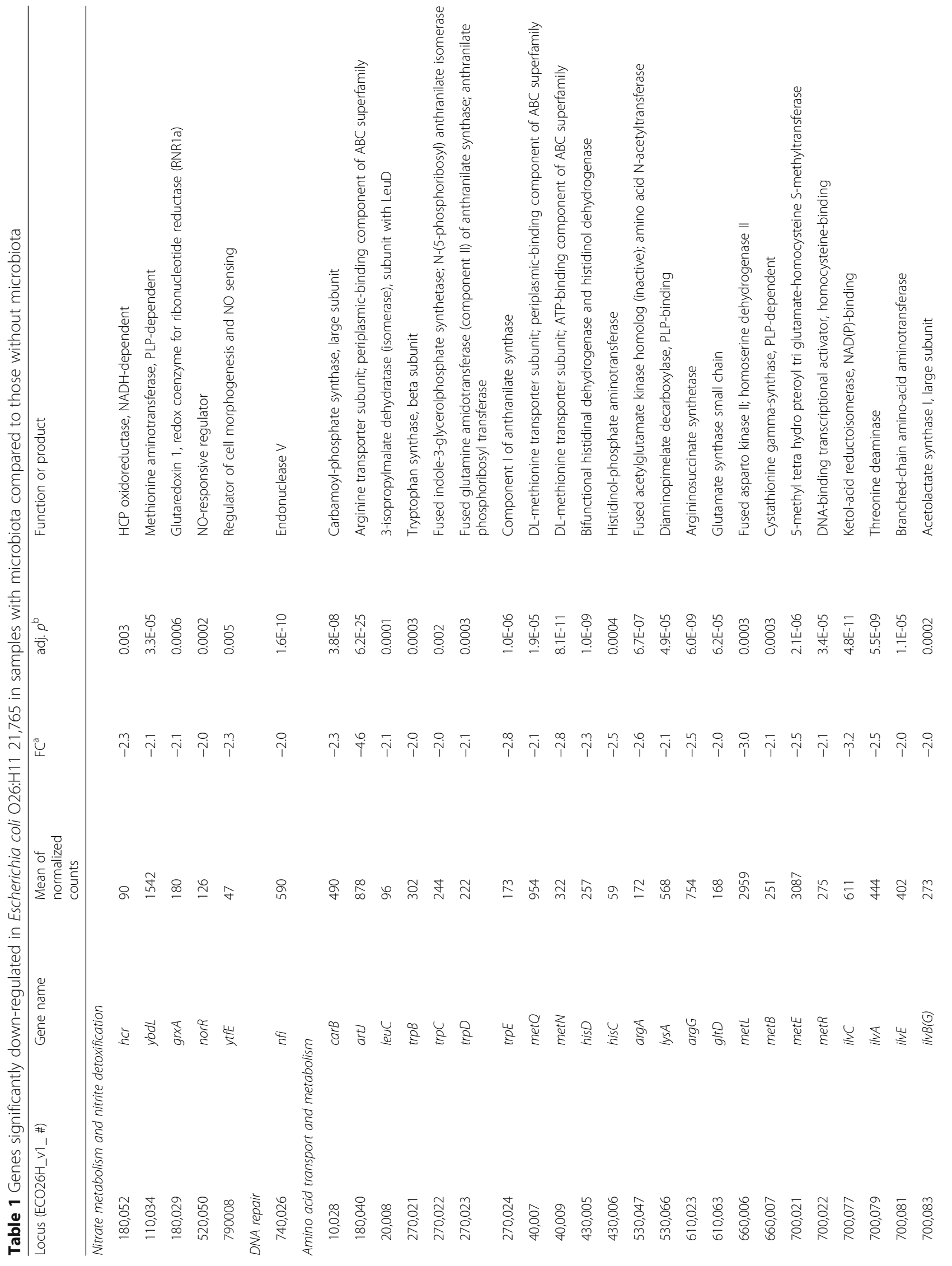




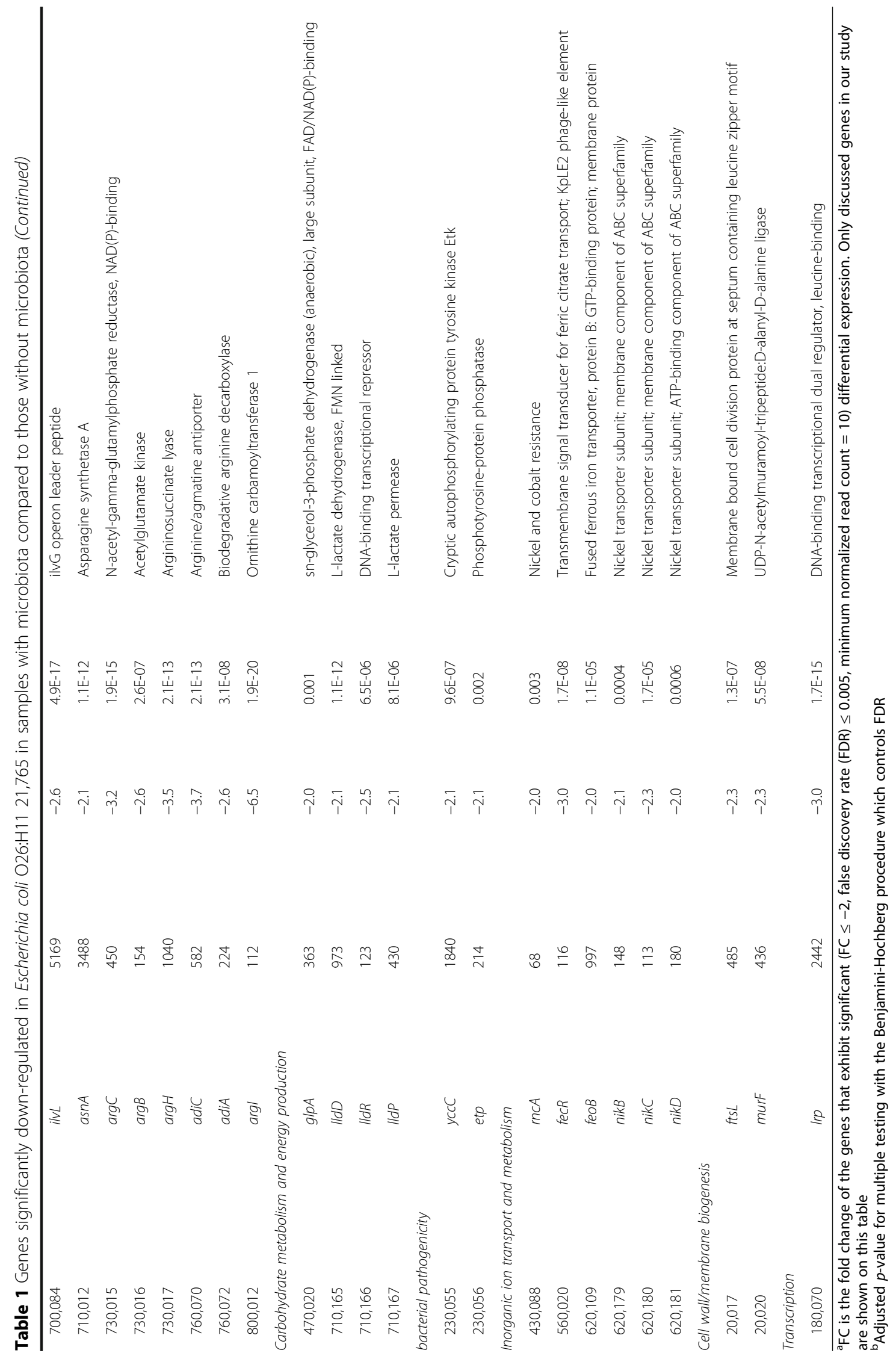




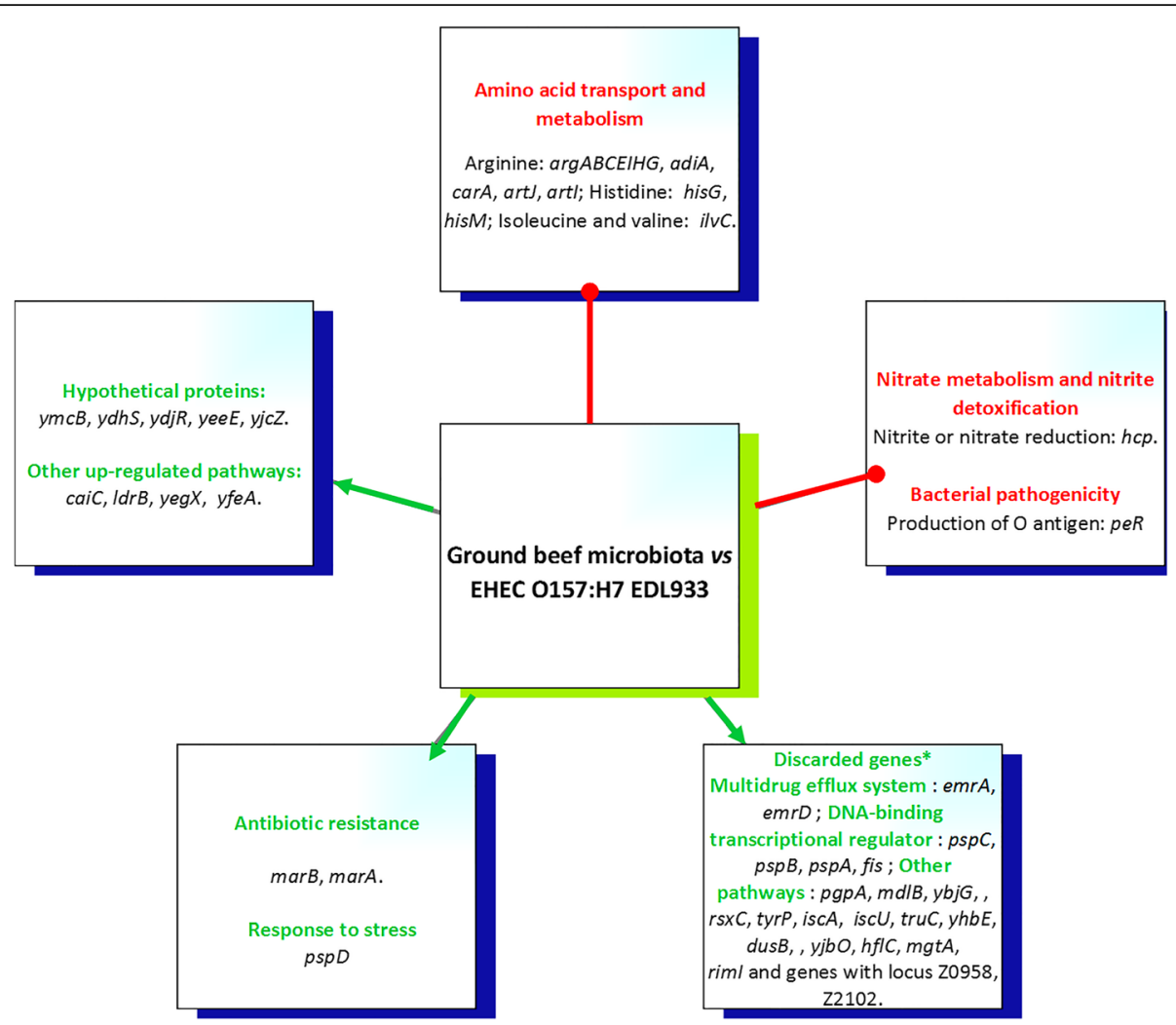

Fig. 4 Summary of the main pathways and regulations affected by background microbiota in Enterohemorrhagic Escherichia coli O157:H7 strain EDL933 in ground beef. Green arrows with head indicate up-regulation and red arrows without head down-regulation. ${ }^{*}$ Genes expected to be up-regulated owing to the possibility of spurious alignment and crosstalk between the reference genome and other similar genomes identified at genus level by $16 \mathrm{~S}$ meta-genomic analysis, were discarded from the study (For discarded genes see Additional file 8: Table S8)

proteins produced by the activity of proteolytic enzymes and peptidases of the background microbiota may enrich the meat with peptides and amino acids and so inhibit the expression of lrp. These data are in accordance with a study led by Tao et al. (1999) which indicated that the expression of many genes involved in the biosynthesis of building blocks, most notably the amino acid biosynthesis pathways, is repressed in high-nutrient environments, as appears to be the case in the present study.

Genes involved in carbohydrate metabolism and energy production Genes implicated in L-lactate metabolism were down-regulated in $\mathrm{O}_{21765}$ (lldR, lldP and $l l d D$ ). L-lactate dehydrogenase (encoded by $l l d D$ ) is a peripheral membrane protein that catalyzes the oxidation of L-lactate to pyruvate. This protein and L-lactate permease (encoded by the $l l d P$ gene) allow $E$. coli to grow in a medium containing L-lactate as the sole carbon source [45]. Transcription of $g l p A$, which encodes a sn-glycerol-3phosphate (G3P) dehydrogenase, GlpA, was also repressed in $\mathrm{O}_{26} 6_{21765}$ (Table 1). Under anaerobic conditions, G3P dehydrogenase GlpA converts G3P to dihydroxyacetone phosphate [46]. This latter compound is converted into
glyceraldehyde-3P entering the gluconeogenesis pathway [47]. Thus, in ground meat, the presence of microbiota seems to repress the transcription of several genes involved in the assimilation of gluconeogenic substrates such as glycerol-3P and L-lactate. These metabolites could be consumed by the background microbiota.

\section{Genes implicated in cell wall/membrane biogenesis} The murF gene encoding the MurF amide ligase enzyme was repressed in $\mathrm{O}_{26} 6_{21765}$ (Table 1). MurF has been shown to be required for catalyzing the final step in the synthesis of bacterial cell wall peptidoglycan and to be essential for bacterial survival [48-51]. The ftsL gene encoding the conserved division protein FtsL was also down-regulated in $\mathrm{O}_{21765}$ (Table 1). FtsL, rather than serving simply as a protein scaffold within the divisome along with its partners FtsB and FtsQ, functions as part of a sensing mechanism that promotes the onset of cell wall remodeling processes needed for the initiation of cell constriction once assembly of the divisome complex is deemed complete [52-54].

In the present study we demonstrated that $m u r F$ and $f t s L$ genes were down-regulated in strain $\mathrm{O} 26_{21765}$ in meat with microbiota. The microbiota may exert an inhibitory 
Table 2 Genes significantly down-regulated in Escherichia coli O157:H7 EDL933 in samples with microbiota compared to those without microbiota

\begin{tabular}{|c|c|c|c|c|c|}
\hline Locus (Z \#) & Gene name & $\begin{array}{l}\text { Mean of } \\
\text { normalized } \\
\text { counts }\end{array}$ & $\mathrm{FC}^{\mathrm{a}}$ & adj. $p^{b}$ & Function or product \\
\hline \multicolumn{6}{|c|}{ Nitrate metabolism and nitrite detoxification } \\
\hline 1107 & hсp & 270 & -2.5 & $3.2 \mathrm{E}-08$ & Hybrid-cluster [4Fe-2S-2O] protein in anaerobic terminal reductases \\
\hline \multicolumn{6}{|c|}{ Amino acid transport and metabolism } \\
\hline 0037 & carA & 369 & -2.3 & $1.8 \mathrm{E}-07$ & Carbamoyl phosphate synthetase small subunit, glutamine amidotransferase \\
\hline 1090 & artJ & 1305 & -4.0 & $8.4 \mathrm{E}-15$ & Arginine transporter subunit; periplasmic-binding component of $A B C$ superfamily \\
\hline 1093 & artl & 407 & -2.0 & 0.0002 & Arginine transporter subunit; periplasmic-binding component of $A B C$ superfamily \\
\hline 3181 & hisG & 221 & -2.0 & 0.001 & ATP phosphoribosyltransferase \\
\hline 3569 & hisM & 208 & -2.0 & 0.0008 & $\begin{array}{l}\text { Histidine/lysine/arginine/ornithine transporter subunit; membrane component of } \\
\text { ABC superfamily }\end{array}$ \\
\hline 4135 & $\arg A$ & 737 & -2.5 & 2.7E-07 & Fused acetylglutamate kinase homolog (inactive); amino acid $\mathrm{N}$-acetyltransferase \\
\hline 4534 & $\arg G$ & 972 & -3.0 & $9.9 \mathrm{E}-12$ & Argininosuccinate synthetase \\
\hline 5285 & $i l v C$ & 773 & -2.0 & 2.1E-05 & Ketol-acid reductoisomerase. NAD(P)-binding \\
\hline 5515 & $\arg E$ & 448 & -2.5 & $2.8 \mathrm{E}-09$ & Acetylornithine deacetylase \\
\hline 5516 & $\operatorname{argC}$ & 1480 & -3.7 & $1.4 \mathrm{E}-16$ & N-acetyl-gamma-glutamylphosphate reductase, NAD(P)-binding \\
\hline 5517 & $\arg B$ & 533 & -2.8 & 1.1E-09 & Acetylglutamate kinase \\
\hline 5518 & $\operatorname{argH}$ & 1496 & -2.5 & $7.2 \mathrm{E}-06$ & Argininosuccinate lyase \\
\hline 5719 & $\operatorname{adiA}$ & 539 & -2.1 & 0.001 & Biodegradative arginine decarboxylase \\
\hline 5866 & $\operatorname{argl}$ & 404 & -2.5 & 0.0006 & Ornithine carbamoyltransferase 1 \\
\hline \multicolumn{6}{|c|}{ bacterial pathogenicity } \\
\hline 3200 & peR & 739 & -2.0 & $6.9 \mathrm{E}-05$ & Perosamine synthetase Per \\
\hline
\end{tabular}

${ }^{\mathrm{a}} \mathrm{FC}$ is the fold change of the genes that exhibit significant $(\mathrm{FC} \leq-2$, false discovery rate $(\mathrm{FDR}) \leq 0.005$, minimum normalized read count $=10)$ differential expression. Only genes discussed in our study are shown on this table

${ }^{\mathrm{b}}$ Adjusted $p$-value for multiple testing with the Benjamini-Hochberg procedure which controls FDR

action on EHEC strains by interfering with the cytokinetic ring apparatus and the synthesis of bacterial cell wall peptidoglycan. Many studies have shown that the growth of EHEC strains in ground beef may be inhibited by background microbiota initially present at levels greater than that of the pathogen $E$. coli $[55,56]$. In our study, the low level of natural microbiota compared to strain $\mathrm{O}_{21} 6_{21765}$ might not sufficiently affect the expression of murF and ftsL genes to halt growth. Both strains (O157 EDL933 and O26 21765 ) were added at an initial level of about 3 logs above that of the natural microbiota. After 7 days of incubation at $12{ }^{\circ} \mathrm{C}$, about $8 \log \mathrm{CFU} / \mathrm{g}$ of each type of natural microbiota (aerobic and LAB) were counted whereas $9 \log$ $\mathrm{CFU} / \mathrm{g}$ of each EHEC strains were enumerated. In the tested conditions, the presence of the meat microbiota at an initial level of about $10^{4} \mathrm{CFU} / \mathrm{g}$ did not impair the growth of either O157 EDL933 or O26 21765 (See Additional file 1: Table S1; Additional file 2: Table S2).

Genes involved in nitrate metabolism and nitrite detoxification The mean raw nitrate content of fresh meat ranged from 18.7 to $38.5 \mathrm{mg} / \mathrm{kg}$ [57]. Microorganisms can reduce nitrate to nitrite, which is partially oxidized to nitrate by sequestering oxygen [58]. The nitrite undergoes chemical reactions that lead to reactive nitrogen species (RNS), including NO [58, 59]. These RNSs can interact with and damage numerous targets, including tyrosine residues, thiols and nucleotide bases [60]. Two down-regulated genes, $h c r$ and $h c p$, were identified in strains $\mathrm{O}_{26} 6_{21765}$ and O157 EDL933 respectively (Tables 1 and 2). They encode the hybrid cluster protein $(\mathrm{HCP})$ and its $\mathrm{NADH}$ oxidoreductase (HCR), respectively, which are supposed to be involved in nitrite or nitrate reduction by an as yet unidentified reaction [61]. In E. coli, hcp has been found to be induced in presence of nitric oxide (NO) under both aerobic and anaerobic conditions [62]. Because of the cytotoxic effects of $\mathrm{NO}$ and its derivatives, E. coli has two prominent ways to detoxify NO: a nitric-oxide reductase (NorVW) and the flavohemoglobin Hmp. The nor $V W$ genes encode flavorubredoxin and flavorubredoxin reductase, respectively, which convert NO to nitrous oxide. In O157 $7_{\mathrm{EDL} 933}$, the norV gene has a 154 bp deletion, resulting in a frameshift mutation. In $\mathrm{O}_{26} 6_{21765}$, the norR gene, encoding an NO-responsive regulator (NorR) [63, 64], was down-regulated (Table 1).

In our study the $y t f E$ gene was down-regulated in $\mathrm{O} 26_{21765}$. The $y t f E$ gene is predicted to encode for a 
cytoplasmic protein, and is annotated as a regulator of cell morphology and NO sensing $[16,65]$. Those authors also showed that YtfE is of major importance in E. coli's response to NO [65].

Other genes that have shown up-regulation in response to nitrosative stress $[62,66]$ were down-regulated in $\mathrm{O} 26_{21765}$. These were the four metBELR genes, involved in methionine biosynthesis or regulation; the gltD gene, which encodes glutamate synthase (NADPH) small chain precursor; $g r x A$, encoding glutaredoxin 1 redox coenzyme ribonucleotide reductase; and $y b d L$, encoding a PLPdependent methionine aminotransferase (Table 1).

Expression of the $n f i$ gene, encoding endonuclease $\mathrm{V}$ (EndoV), was also repressed in $\mathrm{O} 26_{21765}$ grown in ground beef with microbiota. EndoV is a ubiquitous protein responsible for the specific cleavage at the second phosphodiester bond 3' to inosine [67, 68]. In E. coli, many studies have shown that EndoV prevents mutations from nitrosative deamination during nitrate/nitrite respiration [69].

In ground beef with microbiota, raw nitrate content could be metabolized by background microbiota in the meat samples prior to their contamination with EHECs. The up-regulated NO response mechanisms in ground beef without microbiota may allow the pathogen to adapt to sublethal environmental conditions and enhance its resistance to chemicals typically used as preservatives.

Genes implicated in the bacterial pathogenicity of EHECs The $p e R$ gene was down-regulated in strain O157 EDL933 (Table 2). This gene encodes a perosamine synthetase essential for the production of $\mathrm{O}$ antigen. As described by Bilge et al., (1996), an O157:H7 $\Delta p e R$ mutant is significantly more adherent to HeLa cells than is its E. coli $\mathrm{O} 157: \mathrm{H} 7$ parent [70], the mutant strain being deficient in the $\mathrm{O}$ antigen. The $\mathrm{O}$ side chains of bacterial lipopolysaccharide (LPS) may physically hinder contact between the outer membrane and eukaryotic cells. Because of the conserved nature of most EHEC O157 strains, such factors might explain the higher prevalence of O157 EHECs in bovine meat (Zoonose EFSA, 2014). Nevertheless, more data are needed on other O157 EHEC strains.

With $\mathrm{O} 26_{21765}$, the etk and etp genes, which encode a protein-tyrosine kinase, Etk, and a phosphotyrosine-protein phosphatase, Etp, respectively, were down-regulated (Table 1). Various studies have shown that pathogenicity seems to be positively correlated with the level of tyrosine phosphorylation [71, 72]. Increasing evidence supports the idea that tyrosine phosphorylation contributes to several key steps in the infection process, such as adhesion to the host and regulation of pathogenic functions [73-75].

In our study we demonstrated that the expression of the O side chains of bacterial LPS in O157 EDL933, and the level of tyrosine phosphorylation in $\mathrm{O}_{21765}$ were down-regulated in meat with microbiota. Various studies have shown that, the O side chains of bacterial LPS and the level of tyrosine phosphorylation are correlated with the capacity of bacteria to adhere to the eukaryotic cells. Based on these studies, our hypothesis supports the idea that strain $\mathrm{O}_{21765}$ might adhere less well to beef tissue with microbiota than O157 EDL933. These data are in accordance with the higher prevalence of O157 compared to O26 EHECs in ground beef.

Genes implicated in inorganic ion transport and metabolism Iron, nickel and other inorganic ions have various roles in cellular biochemistry. In particular, they are well known as co-factors with a key role in bacterial virulence. For example, it has been established that iron acquisition genes are important contributors to the virulence of uropathogenic E. coli (UPECs) [76]. In our study, several relevant genes were down-regulated in $\mathrm{O}_{21765}$ : the nikBCD genes, encoding one part of the $E$. coli NikABCDE permease. This permease is known to be maximally expressed under anaerobic condition when intracellular nickel is scarce [77, 78]; the $r c n A$ gene, encoding a membrane bound polypeptide, RcnA, described as a cobalt and nickel efflux system in $E$. coli, [79]; the $f e o B$ gene, encoding the polytopic membrane protein, FeoB, which is essential for $\mathrm{Fe}(\mathrm{II})$ uptake [80] (note that $f e o B$ has been described as one of the most prevalent virulence genes in UPECs isolated from patients with community-acquired urinary tract infection [81]); and the fecR gene, encoding the FecR protein, the sensor that recognizes iron (III) dicitrate in the periplasm (Table 1) [82].

The results of the transcriptomic analysis of $\mathrm{O}_{26} 6_{21765}$ suggest that iron and nickel could be more bioavailable in ground beef with microbiota and their transporters might be repressed in response to these external stimuli.

Other down-regulated genes Three (ECO26H_v1_590016; 690,023 and 710,001) and two (Z4363 and 5408) genes annotated as putative transcriptional regulators were down-regulated respectively in $\mathrm{O}_{21765}$ and O157 EDL933 strains (Fig. 3; Fig. 4; Additional file 5: Table S5 and Additional file 7: Table S7). Among them, one (yihL) is shared by the two strains. Several other genes (ECO2 6H_v1_110033; 200,020; 370,007; 430,155; 710,101 and 750,064 in $\mathrm{O}_{21765}$; Z1966 and 3199 in O157 EDL933) $_{2}$ ) were also down-regulated (Additional file 5: Table S5 and Additional file 7: Table S7). Their probable effects as a response to an environmental signal were not discussed in the present study because their functional role has not yet been fully characterized. Moreover, their annotation is based on the presence of conserved amino acid motifs and structural features or limited homology. 
Eleven other genes (ECO26H_v1_120023; 210,002; 220,017; 340,120; 430,059; 500,297; 580,076; 60,012; 670,$016 ; 80,078$ and p30071), annotated as hypothetical or conserved proteins of unknown function, were downregulated in the $\mathrm{O}_{26} 6_{2175}$ strain (Additional file 5: Table S5). Only one (ECO26H_v1_p30071) did not show any significant sequence identity with any of the known genes in the O157 EDL933 strain.

\section{Genes significantly up-regulated in ground meat with microbiota}

Preamble. This is the first study to use strand-specific RNA-seq to investigate the effects of ground beef background microbiota on the overall gene expression of EHEC strains $\mathrm{O} 26_{21765}$ and O157 EDL933. To reduce the effect of spurious alignment and crosstalk between the reference genome of EHEC and other similar genomes, the genes that were transcriptionally up-regulated in the presence of microbiota were filtered for E. coli specific genes (Fig. 1). The down-regulated genes we identified could not be affected by spurious alignment or crosstalk between the reference genomes and other similar genomes, so it was not necessary to apply this filter. A spurious alignment could not generate a false down-regulated gene.

We therefore discarded from our study genes that we expected to be up-regulated in EHEC strains owing to the possibility of spurious alignment and crosstalk between the reference genomes and other similar genomes identified at the genus level by $16 \mathrm{~S}$ metagenomics analysis. The criterion whether or not to discard an up-regulated gene was a score of nucleotide identity (between the altered gene and any other gene provided by GenBank as being part of the genome sequencing data of the identified genus by $16 \mathrm{~S}$ meta-genomic analysis) of more than $50 \%$ across $80 \%$ or more of their length.

This constraint also influenced our sequencing strategy, sequencing mode (paired-end sequencing), library-type (strand-specific cDNA library) and choice of the read length (125 bp). The paired-end strand-specific RNA-Seq with a read length of $125 \mathrm{bp}$ allows for higher levels of specific alignments, thus reducing the possibility of spurious alignment between the reference genome and other similar genomes. Reads with more than one reported alignment were not counted for any feature. We also discarded upregulated genes with identity to any other gene identified as being part of genome sequencing data provided by GenBank and corresponding to the most abundant bacteria identified by $16 \mathrm{~S}$ metagenomics analysis (Figs. 3 and 4). We discarded genes with more than 50\% nucleotide identity across $80 \%$ or more of their length (For discarded genes see Additional file 6: Table S6 and Additional file 8: Table S8). Of the 28 and 35 genes induced in strains $\mathrm{O}_{26} 6_{21765}$ and O157 EDL933 respectively, 14 and 12 passed the filter and are discussed in this study (Tables 3 and 4).
Genes implicated in a detoxification role in EHECs For O157 EDL933, the marA and marB genes, which encode a DNA-binding transcriptional dual activator of multiple antibiotic resistance and a conserved hypothetical protein associated with a multiple antibiotic resistance operon, respectively, were up-regulated (Table 4). The expression of these genes as part of the antibiotic resistance machinery could be activated in response to external stimuli [83], presence of an antibiotic at a sub-lethal concentration being the most common stimulus. In our $16 \mathrm{~S}$ metagenomics study, the genus Serratia represented about 1.5\% of the bacterial population in the ground beef sample inoculated with O157 EDL933 (Fig. 2; Additional file 3: Table S3). Most Serratia spp. have been shown to produce antibiotics. For example, production of carbapenem antibiotics has been demonstrated in Serratia sp. ATCC 39006 [84]. Production of antibiotics has also been reported in Serratia plymuthica RVH1 [85] and Serratia marcescens strain 12 [86]. These observations suggest that the presence of ground beef background microbiota might induce multidrug resistance in EHECs by stimulating transcription of $E$. coli drug resistance genes such as marA, which has been described as sufficient to give $E$. coli multiple antibiotic resistance [87].

Genes implicated in stress response The $p s p D$ gene encoding the peripheral inner membrane phage-shock protein pspD was up-regulated in O157 EDL933 (Table 4). Expression of the $p s p D$ gene is known to be associated with membrane stress and in response to conditions such as phage attack, heat shock and hyperosmotic stress, and exposure to certain metabolites [88, 89]. Thus, the presence of adventitious microbial activity or phage could induce specific stresses in E. coli. However, this needs further investigation.

Other up-regulated genes Several other genes were up-regulated (ECO26H_v1_250,005; p40035; 500,243; 50,040 and Z0043; 3266 respectively, in the $\mathrm{O} 26_{21765}$ and O157EDL933 strains), but their functional roles, based on the presence of conserved amino acid motifs, structural features or limited identity, have not yet been fully characterized (Tables 3 and 4). The effect of their over-expression in response to an environmental signal needs to be identified and they are now new candidates for detailed functional description.

Genes encoding hypothetical proteins Of the 14 and 12 genes studied, 9 and 5 were annotated as unknown or hypothetical proteins in $\mathrm{O}_{21765}$ and O157 ${ }_{\text {EDL933 }}$ strains, respectively (Tables 3 and 4). Two genes (yeeE and $y d h S$ ) were shared between the two strains. Six other (ECO2 6H_v1_260,022; 310,027; 50,014; 510,037; 590,009 and $\mathrm{p} 40014$ ) identified in $\mathrm{O}_{26} 6_{21765}$ strain didn't show any 
Table 3 Genes significantly up-regulated in Escherichia coli O26:H11 21,765 in samples with microbiota compared to those without microbiota

\begin{tabular}{|c|c|c|c|c|c|}
\hline Locus (ECO26H_v1_\#) & Gene name & $\begin{array}{l}\text { Mean of } \\
\text { normalized } \\
\text { counts }\end{array}$ & $\mathrm{FC}^{\mathrm{a}}$ & adj. $p^{\mathrm{b}}$ & Function or product \\
\hline \multicolumn{6}{|c|}{ Unknown or hypothetical proteins } \\
\hline 260022 & $y m g B$ & 101 & 2.1 & 0.0001 & Hypothetical protein \\
\hline 310027 & ydfP & 34 & 2.5 & 0.003 & Conserved hypothetical protein; Qin prophage \\
\hline 340082 & ydhs & 506 & 2.0 & 0.0002 & Conserved hypothetical protein; putative FAD/NAD(P)-binding domain \\
\hline 400008 & yect & 105 & 2.1 & 0.0002 & Hypothetical protein \\
\hline 420013 & yeet & 55 & 2.3 & 0.001 & Conserved hypothetical protein; putative inner membrane protein \\
\hline 50014 & - & 102 & 2.1 & 0.002 & Conserved protein of unknown function \\
\hline 510037 & - & 162 & 2.5 & 3.6E-06 & Protein of unknown function \\
\hline 590009 & - & 61 & 2.1 & 0.004 & Conserved protein of unknown function \\
\hline p40014 & - & 591 & 2.0 & 0.0002 & Conserved protein of unknown function \\
\hline \multicolumn{6}{|l|}{ Other up-regulated genes } \\
\hline 250005 & - & 48 & 2.3 & 0.001 & T3SS secreted effector NleG-like protein \\
\hline 270179 & $y d d x$ & 105 & 2.3 & $8.8 \mathrm{E}-06$ & Putative inner membrane protein \\
\hline 500243 & $y f h R$ & 250 & 2.0 & 7.1E-05 & Putative peptidase \\
\hline 50040 & yhhl & 106 & 2.1 & 0.0007 & Putative transposase \\
\hline p40035 & _- & 99 & 2.3 & 0.0002 & Pilus assembly protein \\
\hline
\end{tabular}

${ }^{\mathrm{a}} \mathrm{FC}$ is the fold change of the genes that exhibit significant ( $\mathrm{FC} \geq 2$, false discovery rate (FDR) $\leq 0.005$, minimum normalized read count $=10$ ) differential expression. Only genes passed the filter are shown on this table. Expected genes to be differentially expressed due to the possibility of spurious alignment, and crosstalk between the reference genome and other similar genomes identified at genus level by $16 \mathrm{~S}$ meta-genomic analysis, were discarded from this study (For discarded genes see Additional file 6: Table S6)

${ }^{\mathrm{b}}$ Adjusted $p$-value for multiple testing with the Benjamini-Hochberg procedure which controls FDR

Table 4 Genes significantly up-regulated in E. coli O157:H7 EDL933 in samples with microbiota compared to those without microbiota

\begin{tabular}{|c|c|c|c|c|c|}
\hline Locus (Z \#) & Gene name & $\begin{array}{l}\text { Mean of } \\
\text { normalized } \\
\text { counts }\end{array}$ & $\mathrm{FC}^{\mathrm{a}}$ & adj. $p^{b}$ & Function or product \\
\hline \multicolumn{6}{|c|}{ Antibiotic resistance } \\
\hline 2169 & $\operatorname{mar} B$ & 78 & 2.6 & $8.2 \mathrm{E}-06$ & Conserved hypothetical protein associated with multiple antibiotic resistance operon \\
\hline 2170 & marA & 133 & 2.1 & $2.1 \mathrm{E}-05$ & DNA-binding transcriptional dual activator of multiple antibiotic resistance \\
\hline \multicolumn{6}{|c|}{ Response to stress } \\
\hline 2478 & $p s p D$ & 74 & 2.6 & $2.2 \mathrm{E}-05$ & Peripheral inner membrane phage-shock protein \\
\hline \multicolumn{6}{|c|}{ Hypothetical proteins } \\
\hline 1402 & $y m c B$ & 102 & 2.1 & 0.0004 & Conserved hypothetical protein \\
\hline 2695 & $y d h S$ & 1115 & 2.0 & 0.0001 & Conserved hypothetical protein; putative FAD/NAD(P)-binding domain \\
\hline 2774 & $y d j R$ & 206 & 2.3 & 0.0004 & Conserved hypothetical protein \\
\hline 3175 & yeeE & 143 & 2.8 & 1.7E-07 & Conserved hypothetical protein; putative inner membrane protein \\
\hline 5712 & yjcZ & 173 & 2.1 & 0.0002 & Conserved hypothetical protein \\
\hline \multicolumn{6}{|c|}{ Other up-regulated genes } \\
\hline 0043 & caic & 204 & 2.0 & 0.0005 & Putative crotonobetaine CoA ligase:carnitine CoA ligase \\
\hline 1987 & $I d r B$ & 176 & 2.0 & 0.001 & Fragment of small toxic polypeptide (partial) \\
\hline 3266 & yeg $x$ & 100 & 2.3 & 0.0002 & Putative membrane-bound hydrolase \\
\hline 3660 & yfeA & 3551 & 2.0 & $2.9 \mathrm{E}-05$ & Putative diguanylate cyclase \\
\hline
\end{tabular}

${ }^{\mathrm{a}} \mathrm{FC}$ is the fold change of the genes that exhibit significant ( $\mathrm{FC} \geq 2$, false discovery rate (FDR) $\leq 0.005$, minimum normalized read count $=10$ ) differential expression. Only genes passed the filter are shown on this table. Expected genes to be differentially expressed due to the possibility of spurious alignment, and crosstalk between the reference genome and other similar genomes identified at genus level by $16 \mathrm{~S}$ meta-genomic analysis, were discarded from this study (For discarded genes see Additional file 8: Table S8)

${ }^{\mathrm{b}}$ Adjusted $p$-value for multiple testing with the Benjamini-Hochberg procedure which controls FDR 
significant sequence identity with any gene of the other one. In EHEC, about one third of the genes are still annotated as hypothetical [89]. Genes annotated as hypothetical and up-regulated in presence of naturel microbiota, are now new candidates for a detailed functional description.

\section{Conclusions}

This article demonstrates how RNA-Seq coupled with 16S metagenomics analysis can be used to discover new and relevant impacts on the functions of an individual microbe within a complex environmental community. The methodology developed was designed for describing the effects of ground beef background microbiota on the overall gene expression of EHEC strains $\mathrm{O}_{26} 6_{21765}$ and O157 EDL933 by comparison with their behavior in beef with no microbiota. For our experimental design, the choice of two strains, one isolated from Michigan ground beef (O157 EDL933 $_{\text {und }}$ and one from human fecal samples $\left(\mathrm{O}_{26} 6_{21765}\right)$, enabled us to gain information of continuing importance for understanding the biology of EHECs in general and the strain-specific adaptations of strains O157 EDL933 $_{2}$ and $\mathrm{O}_{21765}$ in particular.

In strain $\mathrm{O}_{26} 6_{21765}, 95$ genes were expressed at significantly lower levels in ground beef samples with microbiota, and 28 were significantly up-regulated. The corresponding numbers for down- and up-regulated genes in O157 EDL933 were 21 and 25 . Together, all the genes identified in the present study serve as a starting point for developing testable hypotheses about the mechanisms underlying the organism's adaptations to different habitats, including the evolution of its virulence. Moreover, genes that are altered in presence of natural microbiota, notably genes for the category of the hypothetical proteins, are now new targets for studying interactions between microorganisms. Finally, murF and ftsL exemplarily show that transcriptome profiling will be a powerful technique for designing novel therapeutic approaches, since treating an EHEC infection with antibiotics can potentiate the disease.

Tremendous diversity exists within the meat microbiota and changing experimental conditions such as storage conditions will alter the microbial population $[90,91]$ and so change its interaction mechanisms. As this new methodology is not tied to particular conditions, it can be used with any other conditions, where it would screen for new interaction mechanisms.

\section{Additional files}

Additional file 1: Table S1. Total viable counts of natural microbiota detected in the ground beef held at $12{ }^{\circ} \mathrm{C}$ and prepared from the outer part of the muscle. (DOC $29 \mathrm{~kb}$ )

Additional file 2: Table S2. Population over time of two strains of enterohemorrhagic Escherichia coli (O157:H7 EDL933 and O26:H11 21,765) grown in ground beef held at $12^{\circ} \mathrm{C}$ and prepared from the outer or inner part of the muscle. (DOC $30 \mathrm{~kb}$ )
Additional file 3: Table S3. Genus level distribution of sequences based on the $16 \mathrm{~S}$ rRNA gene libraries constructed from a ground beef sample with natural microflora (A) and ground beef samples inoculated with E. coli O26:H11 21,765 (B) or E. coli 0157:H7 EDL933 (C) strains. (DOC $55 \mathrm{~kb}$ )

Additional file 4: Table S4. Summary of enterohemorrhagic Escherichia coli cDNA samples sequenced in ground beef with or without microbiota (DOC $41 \mathrm{~kb}$ )

Additional file 5: Table S5. Others down-regulated genes in Escherichia coli O26:H11 21,765 in samples with microbiota compared to those without microbiota. (DOC $95 \mathrm{~kb}$ )

Additional file 6: Table S6. Discarded up-regulated genes in Escherichia coli O26:H11 21,765 in samples with microbiota compared to those without microbiota. (DOC 51 kb)

Additional file 7: Table S7. Others down-regulated genes in Escherichia coli 0157:H7 EDL933 in samples with microbiota compared to those without microbiota. (DOC $36 \mathrm{~kb}$ )

Additional file 8: Table S8. Discarded up-regulated genes in Escherichia coli 0157:H7 EDL933 in samples with microbiota compared to those without microbiota. (DOC $62 \mathrm{~kb}$ )

\section{Abbreviations}

BHI: Brain heart infusion; bp: Base pairs; BPW: Buffered peptone; CDNA: Complementary DNA; CDS: Coding DNA sequence; CFU: Colonyforming units; DE: Differential expression; DNA: Deoxyribonucleic acid; E.: coli; EFSA: European food safety authority; EHEC: Enterohemorrhagic Escherichia coli; EU: European Union; FDR: False discovery rate; GLM: Generalized linear model; HCP: Hybrid cluster protein; HUS: Hemolytic-uremic syndrome; LAB: Lactic acid bacteria; LPS: LipoPolySaccharide; NO: Nitric oxide; ORF: Open reading frame; OUT: Operational taxonomic unit; PCA: Plate-count agar; PCR: Polymerase chain reaction; RNS: Reactive nitrogen species; rRNA: Ribosomal ribonucleic acid; RTE: Ready-To-Eat; STEC: Shiga toxine E. coli; UPEC: UroPathogenic

\section{Acknowledgments}

The authors are grateful to the LABGeM team and the National Infrastructure "France Genomique" for the functional annotation. This work was performed using the galaxy.prabi.fr web service and the computing facilities of the LBBE/ PRABI. The authors thank Harriet Coleman for English proofreading. The authors also thank Patricia Mariani (Hospital Robert Debré, France) who kindly provided the strain O26:H11 21765.

\section{Funding}

This study was supported by "FEDER (Fonds Européen de Développement Régional) and CPER (Contrat de Plan État-Région) ASTERisk (Auvergne STEC Risque)", Auvergne region. This work was also supported by the institute of VetAgro Sup. The funding bodies had no role in study design, data collection and analysis, decision to publish, or preparation of the manuscript. Delphine Thevenot-Sergentet obtained additive funding for performing experiments. Francoise Leriche, Stéphanie Blanquet-Diot and Delphine Thevenot-Sergentet obtained funding for Postdoc salary.

\section{Availability of data and materials}

Sequencing reads from RNA-seq analysis are available at the European Nucleotide Archive under study number PRJEB13600 (ERS1127228-ERS1127233; ERS1127235-ERS1127239; ERS1138027). Sequencing reads from 165 metagenomics analysis are available at the European Nucleotide Archive under study number PRJEB13580 (ERS1119543-ERS1119545).

\section{Authors' contributions}

DS, FL, SB and WG involved in steering committee of the project. DS and WG conceived and designed the experiments. WG performed the experiments. WG and CG prepared the samples. SC, VN and AD provided tools for bioinformatics analysis. WG performed bioinformatics analyses, interpreted the data and wrote the manuscript. FL, DS and SB significantly contributed to the revision of the manuscript. All authors participated in the acquisition of data and the revision of the manuscript. All authors read and approved the final version to be published. All authors agreed to be accountable for all aspects of the work in ensuring that questions related to the accuracy or integrity of any part of the work are appropriately investigated and resolved. 


\section{Ethics approval and consent to participate}

All data were collected in accordance with the European Parliament and Council decision for the epidemiological surveillance and control of communicable disease in the European community. Ethical approval and informed consent were not required.

\section{Consent for publication}

Not applicable.

\section{Competing interests}

The authors declare that they have no competing interests.

\section{Publisher's Note}

Springer Nature remains neutral with regard to jurisdictional claims in published maps and institutional affiliations.

\begin{abstract}
Author details
'UMR 5557 Ecologie Microbienne, Research Group on Bacterial Opportunistic Pathogens and Environment, CNRS, VetAgro Sup and Université de Lyon, Lyon, France. ${ }^{2}$ Université Clermont Auvergne, INRA, UMRF, F-15000 Aurillac, France. ${ }^{3}$ UMR UCA INRA 454 MEDIS Microbiota Digestive environment and Health, Université Clermont Auvergne, 63000 Clermont-Ferrand, France. ${ }^{4}$ VetAgro Sup, Campus Agronomique de Lempdes, Lempdes, France. ${ }^{5}$ Alternative Energies and Atomic Energy Commission (CEA), Genomic Institute Genoscope \& CNRS-UMR8030 \& Evry University, Laboratory of Bioinformatics Analysis in Genomics and Metabolism, Evry, France. ${ }^{6} \mathrm{PRAB}$, Rhône Alpes Bioinformatics Center, UCBL, Lyon1, Université de Lyon, Lyon, France. ${ }^{7}$ UMR 5557 Ecologie Microbienne, CNRS, Université de Lyon, Lyon, France. ${ }^{8}$ Reference Laboratory for Escherichia coli including Shiga Toxin-Producing E. coli, VetAgro Sup, Campus Vétérinaire de Lyon, Université de Lyon, Marcy l'Etoile, Lyon, France.
\end{abstract}

Received: 13 March 2017 Accepted: 24 July 2017

Published online: 03 August 2017

\section{References}

1. Van Vliet AHM. Next generation sequencing of microbial transcriptomes: challenges and opportunities. FEMS Microbiol Lett. 2010;302:1-7.

2. Creecy JP, Conway T. Quantitative bacterial transcriptomics with RNA-seq. Curr Opin Microbiol 2015:0:133-140.

3. Frias-Lopez J, Shi Y, Tyson GW, Coleman ML, Schuster SC, Chisholm SW, et al. Microbial community gene expression in ocean surface waters. Proc Natl Acad Sci U S A. 2008;105:3805-10.

4. Gilbert JA, Field D, Huang Y, Edwards R, Li W, Gilna P, et al. Detection of large numbers of novel sequences in the Metatranscriptomes of complex marine microbial communities. PLoS One. 2008;3:e3042.

5. Rey FE, Faith JJ, Bain J, Muehlbauer MJ, Stevens RD, Newgard CB, et al. Dissecting the in vivo metabolic potential of two human gut Acetogens. J Biol Chem. 2010;285:22082-90.

6. Turnbaugh PJ, Quince C, Faith JJ, McHardy AC, Yatsunenko T, Niazi F, et al. Organismal, genetic, and transcriptional variation in the deeply sequenced gut microbiomes of identical twins. Proc Natl Acad Sci U S A. 2010;107:7503-8.

7. Rowe PC, Orrbine E, Lior H, Wells GA, Yetisir E, Clulow M, et al. Risk of hemolytic uremic syndrome after sporadic Escherichia Coli O157:H7 infection: results of a Canadian collaborative study. J Pediatr. 1998;132:777-82.

8. Tserenpuntsag B, Chang H-G, Smith PF, Morse DL. Hemolytic uremic syndrome risk and Escherichia Coli O157:H7. Emerg Infect Dis. 2005;11:1955-7.

9. Sarimehmetoglu B, Aksoy MH, Ayaz ND, Ayaz Y, Kuplulu O, Kaplan YZ. Detection of Escherichia Coli O157:H7 in ground beef using immunomagnetic separation and multiplex PCR. Food Control. 2009;20:357-61.

10. Renter DG, Sargeant JM, Oberst RD, Samadpour M. Diversity, frequency, and persistence of Escherichia Coli 0157 strains from range cattle environments. Appl Environ Microbiol. 2003;69:542-7.

11. Barkocy-Gallagher GA, Arthur TM, Rivera-Betancourt M, Nou X, Shackelford SD, Wheeler TL, et al. Seasonal prevalence of Shiga toxin-producing Escherichia Coli, including 0157:H7 and non-O157 serotypes, and salmonella in commercial beef processing plants. J Food Prot. 2003;66:1978-86.

12. European Food Safety Authority, European Centre for Disease Prevention and Control (ECDC). The European Union summary report on trends and sources of zoonoses, zoonotic agents and food-borne outbreaks in 2014.
EFSA J. [Internet]. 2015 [cited 2017 Jul 28];13. Available from: http://doi. wiley.com/10.2903/j.efsa.2015.4329.

13. King LA, Loukiadis E, Mariani-Kurkdjian P, Haeghebaert S, Weill F-X, Baliere C, et al. Foodborne transmission of sorbitol-fermenting Escherichia Coli O157: [H7] via ground beef: an outbreak in northern France, 2011. Clin. Microbiol. Infect. Off. Publ. Eur. Soc. Clin. Microbiol. Infect. Dis. 2014;20:01136-44.

14. Kostrzynska M, Bachand A. Use of microbial antagonism to reduce pathogen levels on produce and meat products: a review. Can J Microbiol. 2006;52:1017-26.

15. Hartmann HA, Wilke T, Erdmann R. Efficacy of bacteriocin-containing cellfree culture supernatants from lactic acid bacteria to control listeria monocytogenes in food. Int J Food Microbiol. 2011;146:192-9.

16. Galia W, Mariani-Kurkdjian P, Loukiadis E, Blanquet-Diot S, Leriche F, Brugère H, et al. Genome sequence and annotation of a human infection isolate of Escherichia Coli O26:H11 involved in a raw milk cheese outbreak. Genome Announc. 2015;3

17. Riley LW, Remis RS, Helgerson SD, McGee HB, Wells JG, Davis BR, et al. Hemorrhagic colitis associated with a rare Escherichia Coli serotype. N Engl J Med. 1983;308:681-5.

18. Perelle S, Dilasser F, Grout J, Fach P. Detection by 5'-nuclease PCR of Shigatoxin producing Escherichia Coli O26, O55, O91, O103, O111, O113, O145 and $0157: \mathrm{H7}$, associated with the world's most frequent clinical cases. Mol Cell Probes. 2004;18:185-92.

19. Berry ED, Koohmaraie M. Effect of different levels of beef bacterial microflora on the growth and survival of Escherichia Coli 0157:H7 on beef carcass tissue. J Food Prot. 2001;64:1138-44.

20. Andreotti R, Pérez de León AA, Dowd SE, Guerrero FD, Bendele KG, Scoles GA. Assessment of bacterial diversity in the cattle tick Rhipicephalus (Boophilus) microplusthrough tag-encoded pyrosequencing. BMC Microbiol. 2011;11:6.

21. Schloss PD, Westcott SL, Ryabin T, Hall JR, Hartmann M, Hollister EB, et al. Introducing mothur: open-source, platform-independent, communitysupported software for describing and comparing microbial communities. Appl Environ Microbiol. 2009;75:7537-41.

22. Pruesse E, Quast C, Knittel K, Fuchs BM, Ludwig W, Peplies J, et al. SILVA: a comprehensive online resource for quality checked and aligned ribosomal RNA sequence data compatible with ARB. Nucleic Acids Res. 2007;35:7188-96.

23. Bacci G, Bani A, Bazzicalupo M, Ceccherini MT, Galardini M, Nannipieri P, et al. Evaluation of the performances of ribosomal database project (RDP) classifier for taxonomic assignment of 16S rRNA Metabarcoding sequences generated from Illumina-Solexa NGS. J Genomics. 2015;3:36-9.

24. Wang Q, Garrity GM, Tiedje JM, Cole JR. Naive Bayesian classifier for rapid assignment of rRNA sequences into the new bacterial taxonomy. Appl Environ Microbiol. 2007;73:5261-7.

25. Nielsen EM, Andersen MT. Detection and characterization of verocytotoxinproducing Escherichia Coli by automated 5' nuclease PCR assay. J Clin Microbiol. 2003;41:2884-93.

26. Schroeder A, Mueller O, Stocker S, Salowsky R, Leiber M, Gassmann M, et al. The RIN: an RNA integrity number for assigning integrity values to RNA measurements. BMC Mol Biol. 2006;7:3.

27. Levin JZ, Yassour M, Adiconis X, Nusbaum C, Thompson DA, Friedman N, et al. Comprehensive comparative analysis of strand-specific RNA sequencing methods. Nat Methods. 2010;7:709-15.

28. Parkhomchuk D, Borodina T, Amstislavskiy V, Banaru M, Hallen L, Krobitsch S, et al. Transcriptome analysis by strand-specific sequencing of complementary DNA. Nucleic Acids Res. 2009;37:e123.

29. Blankenberg D, Von Kuster G, Coraor N, Ananda G, Lazarus R, Mangan M, et al. Galaxy: a web-based genome analysis tool for experimentalists. In: Ausubel Al FM, editor. Curr. Protoc. Mol. Biol. Ed; 2010. Chapter 19:Unit 19.10.1-21.

30. Giardine B, Riemer C, Hardison RC, Burhans R, Elnitski L, Shah P, et al. Galaxy: a platform for interactive large-scale genome analysis. Genome Res. 2005;15:1451-5.

31. Goecks J, Nekrutenko A, Taylor J. Galaxy team. Galaxy: a comprehensive approach for supporting accessible, reproducible, and transparent computational research in the life sciences. Genome Biol. 2010;11:R86.

32. Martin M. Cutadapt removes adapter sequences from high-throughput sequencing reads. EMBnetjournal. 2011;17:10-2.

33. Bolger AM, Lohse M, Usadel B. Trimmomatic: a flexible trimmer for Illumina sequence data. Bioinforma Oxf Engl. 2014;30:2114-20.

34. Langmead B, Trapnell C, Pop M, Salzberg SL. Ultrafast and memory-efficient alignment of short DNA sequences to the human genome. Genome Biol. 2009;10:R25.

35. Anders S, Pyl PT, Huber W. HTSeq - a python framework to work with highthroughput sequencing data. Bioinformatics. 2015;31:166-9. 
36. Perna NT, Plunkett G, Burland V, Mau B, Glasner JD, Rose DJ, et al. Genome sequence of enterohaemorrhagic Escherichia Coli 0157:H7. Nature. 2001; 409:529-33.

37. Love Ml, Huber W, Anders S. Moderated estimation of fold change and dispersion for RNA-seq data with DESeq2. bioRxiv. 2014;002832.

38. Anders S, Huber W. Differential expression analysis for sequence count data. Genome Biol. 2010;11:R106

39. $\mathrm{YH}$ Benjamini $\mathrm{YH}$. Controlling the false discovery rate - a practical and powerful approach to multiple testing. J R Stat Soc Ser B. 1995;57:289-300.

40. Vallenet D, Belda E, Calteau A, Cruveiller S, Engelen S, Lajus A, et al. MicroScopean integrated microbial resource for the curation and comparative analysis of genomic and metabolic data. Nucleic Acids Res. 2013;41:D636-47.

41. Leisner JJ, Laursen BG, Prévost H, Drider D, Dalgaard P. Carnobacterium: positive and negative effects in the environment and in foods. FEMS Microbiol Rev. 2007:31:592-613.

42. Haas BJ, Chin M, Nusbaum C, Birren BW, Livny J. How deep is deep enough for RNA-Seq profiling of bacterial transcriptomes? BMC Genomics. 2012;13:734.

43. Tao H, Bausch C, Richmond C, Blattner FR, Conway T. Functional genomics: expression analysis of Escherichia Coli growing on minimal and Rich Media. J Bacteriol. 1999;181:6425-40.

44. Chen CF, Lan J, Korovine M, Shao ZQ, Tao L, Zhang J, et al. Metabolic regulation of Irp gene expression in Escherichia Coli K-12. Microbiology. 1997;143:2079-84.

45. Dong JM, Taylor JS, Latour DJ, luchi S, Lin EC. Three overlapping Ict genes involved in L-lactate utilization by Escherichia Coli. J Bacteriol. 1993;175:6671-8.

46. Cole ST, Eiglmeier K, Ahmed S, Honore N, Elmes L, Anderson WF, et al. Nucleotide sequence and gene-polypeptide relationships of the glpABC operon encoding the anaerobic sn-glycerol-3-phosphate dehydrogenase of Escherichia Coli K-12. J Bacteriol. 1988;170:2448-56.

47. Bertin Y, Deval C, de la Foye A, Masson L, Gannon V, Harel J, et al. The gluconeogenesis pathway is involved in maintenance of Enterohaemorrhagic Escherichia Coli O157:H7 in bovine intestinal content. PLoS One. 2014;9:e98367.

48. Baum EZ, Crespo-Carbone SM, Abbanat D, Foleno B, Maden A, Goldschmidt R, et al. Utility of muropeptide ligase for identification of inhibitors of the cell wall biosynthesis enzyme MurF. Antimicrob Agents Chemother. 2006;50:230-6.

49. Baum EZ, Crespo-Carbone SM, Klinger A, Foleno BD, Turchi I, Macielag M, et al. A MurF inhibitor that disrupts cell wall biosynthesis in Escherichia Coli. Antimicrob Agents Chemother. 2007;51:4420-6.

50. Baum EZ, Crespo-Carbone SM, Foleno BD, Simon LD, Guillemont J, Macielag $M$, et al. MurF inhibitors with antibacterial activity: effect on muropeptide levels. Antimicrob Agents Chemother. 2009;53:3240-7.

51. Paradis-Bleau C, Lloyd A, Sanschagrin F, Clarke T, Blewett A, Bugg TD, et al. Phage display-derived inhibitor of the essential cell wall biosynthesis enzyme MurF. BMC Biochem. 2008;9:33.

52. Gonzalez MD, Akbay EA, Boyd D, Beckwith J. Multiple interaction domains in FtsL, a protein component of the widely conserved bacterial FtsLBQ cell division complex. J Bacteriol. 2010;192:2757-68.

53. Liu B, Persons L, Lee L, de Boer PAJ. Roles for both FtsA and the FtsBLQ subcomplex in FtsN-stimulated cell constriction in E scherichia coli: cell fission regulation by FtsN. FtsA and FtsBLQ Mol Microbiol. 2015;95:945-70.

54. Tsang M-J, Bernhardt TG. A role for the FtsQLB complex in cytokinetic ring activation revealed by an $\mathrm{fts} L$ allele that accelerates division. Mol Microbiol. 2015;95:925-44.

55. Palumbo SA, Pickard A, Call JE. Population changes and Verotoxin production of Enterohemorrhagic Escherichia Coli strains inoculated in milk and ground beef held at low temperatures. J Food Prot. 1997;60:746-50.

56. Vold L, Holck A, Wasteson $Y$, Nissen $H$. High levels of background flora inhibits growth of Escherichia Coli 0157:H7 in ground beef. Int J Food Microbiol. 2000; 56:219-25.

57. Hsu J, Arcot J, Alice LN. Nitrate and nitrite quantification from cured meat and vegetables and their estimated dietary intake in Australians. Food Chem. 2009;115:334-9.

58. Honikel K-O. The use and control of nitrate and nitrite for the processing of meat products. Meat Sci. 2008;78:68-76.

59. Hammes WP. Metabolism of nitrate in fermented meats: the characteristic feature of a specific group of fermented foods. Food Microbiol. 2012;29:151-6.

60. Gaupp R, Ledala N, Somerville GA. Staphylococcal response to oxidative stress. Front Cell Infect Microbiol. 2012;2:33.

61. Filenko NA, Browning DF, Cole JA. Transcriptional regulation of a hybrid cluster (prismane) protein. Biochem Soc Trans. 2005;33:195-7.

62. Flatley J, Barrett J, Pullan ST, Hughes MN, Green J, Poole RK. Transcriptional responses of Escherichia Coli to S-nitrosoglutathione under defined chemostat conditions reveal major changes in methionine biosynthesis. J Biol Chem. 2005;280:10065-72.

63. Gardner AM, Helmick RA, Gardner PR. Flavorubredoxin, an inducible catalyst for nitric oxide reduction and detoxification in Escherichia Coli. J Biol Chem. 2002;277:8172-7.

64. Hutchings MI, Mandhana N, Spiro S. The NorR protein of Escherichia Coli activates expression of the Flavorubredoxin gene norV in response to reactive nitrogen species. J Bacteriol. 2002;184:4640-3.

65. Justino MC, Vicente JB, Teixeira M, Saraiva LM. New genes implicated in the protection of anaerobically grown Escherichia Coli against nitric oxide. J Biol Chem. 2005;280:2636-43.

66. Roos $\mathrm{V}$, Klemm P. Global gene expression profiling of the asymptomatic bacteriuria Escherichia Coli strain 83972 in the human urinary tract. Infect Immun. 2006;74:3565-75.

67. Gates FT, Linn S. Endonuclease V of Escherichia Coli. J Biol Chem. 1977;252:1647-53.

68. Guo G, Ding Y, Weiss B. Nfi, the gene for endonuclease $V$ in Escherichia Coli K-12. J. Bacteriol. 1997:179:310-6.

69. Weiss B. Endonuclease $V$ of Escherichia coli prevents mutations from nitrosative deamination during nitrate/nitrite respiration. Mutat Res Repair. 2001:461:301-9.

70. Bilge SS, Vary JC, Dowell SF, Tarr PI. Role of the Escherichia Coli O157:H7 $\mathrm{O}$ side chain in adherence and analysis of an rfb locus. Infect Immun. 1996;64:4795-801.

71. Ravichandran A, Sugiyama N, Tomita M, Swarup S, Ishihama Y. Ser/Thr/Tyr phosphoproteome analysis of pathogenic and non-pathogenic pseudomonas species. Proteomics. 2009;9:2764-75.

72. Ruiguang Ge WS. Bacterial Phosphoproteomic analysis reveals the correlation between protein phosphorylation and bacterial pathogenicity. Genomics Proteomics Amp Bioinforma. 2011;9:119-27.

73. Jers C, Soufi B, Grangeasse C, Deutscher J, Mijakovic I. Phosphoproteomics in bacteria: towards a systemic understanding of bacterial phosphorylation networks. Expert Rev Proteomics. 2008;5:619-27.

74. Kenny B, DeVinney R, Stein M, Reinscheid DJ, Frey EA, Finlay BB. Enteropathogenic $E$. coli (EPEC) transfers its receptor for intimate adherence into mammalian cells. Cell 1997:91:511-520.

75. Soufi B, Jers C, Hansen ME, Petranovic D, Mijakovic I. Insights from site-specific phosphoproteomics in bacteria. Biochim Biophys Acta. 1784;2008:186-92.

76. Snyder JA, Haugen BJ, Buckles EL, Lockatell CV, Johnson DE, Donnenberg MS, et al. Transcriptome of Uropathogenic Escherichia Coli during urinary tract infection. Infect Immun. 2004;72:6373-81.

77. Chivers PT, Sauer RT. Regulation of high affinity nickel uptake in bacteria Ni2+ -DEPENDENT INTERACTION OF NikR WITH WILD-TYPE AND MUTANT OPERATOR SITES. J Biol Chem. 2000;275:19735-41.

78. Pina KD, Desjardin V, Mandrand-Berthelot M-A, Giordano G, Wu L-F. Isolation and characterization of thenikR gene encoding a nickel-responsive regulator inEscherichia coli. J Bacteriol. 1999:181:670-4.

79. Rodrigue A, Effantin G, Mandrand-Berthelot M-A. Identification of rcnA (yohM), a nickel and cobalt resistance gene in Escherichia Coli. J Bacteriol. 2005;187:2912-6.

80. Marlovits TC, Haase W, Herrmann C, Aller SG, Unger VM. The membrane protein FeoB contains an intramolecular $\mathrm{G}$ protein essential for $\mathrm{Fe}(\mathrm{II})$ uptake in bacteria. Proc Natl Acad Sci U S A. 2002:99:16243-8.

81. Zhao L, Chen X, Zhu X, Yang W, Dong L, Xu X, et al. Prevalence of virulence factors and antimicrobial resistance of uropathogenic Escherichia Coli in Jiangsu province (China). Urology. 2009;74:702-7.

82. Van Hove B, Staudenmaier H, Braun V. Novel two-component transmembrane transcription control: regulation of iron dicitrate transport in Escherichia Coli K-12. J Bacteriol. 1990;172:6749-58.

83. Levy SB. Active efflux, a common mechanism for biocide and antibiotic resistance. Symp Ser Soc Appl Microbiol. 2002:65S-71S.

84. Parker WL, Rathnum ML, Wells JS, Trejo WH, Principe PA, Sykes RB. SQ 27,860, a simple carbapenem produced by species of Serratia and Erwinia. J. Antibiot. (Tokyo). 1982:35:653-60.

85. Van Houdt R, Moons P, Aertsen A, Jansen A, Vanoirbeek K, Daykin M, et al. Characterization of a luxl/luxR-type quorum sensing system and $\mathrm{N}$-acylhomoserine lactone-dependent regulation of exo-enzyme and antibacterial component production in Serratia plymuthica RVH1. Res Microbiol. 2007; 158:150-8.

86. Coulthurst SJ, Williamson NR, Harris AKP, Spring DR, Salmond GPC. Metabolic and regulatory engineering of Serratia Marcescens: mimicking phage-mediated horizontal acquisition of antibiotic biosynthesis and quorum-sensing capacities. Microbiol Read Engl. 2006;152:1899-911. 
87. Gambino L, Gracheck SJ, Miller PF. Overexpression of the MarA positive regulator is sufficient to confer multiple antibiotic resistance in Escherichia Coli. J Bacteriol. 1993;175:2888-94.

88. Jovanovic G, Lloyd L, Stumpf MPH, Mayhew AJ, Buck M. Induction and function of the phage shock protein extracytoplasmic stress response in Escherichia Coli. J Biol Chem. 2006;281:21147-61.

89. Landstorfer R, Simon S, Schober S, Keim D, Scherer S, Neuhaus K. Comparison of strand-specific transcriptomes of enterohemorrhagic Escherichia Coli O157:H7 EDL933 (EHEC) under eleven different environmental conditions including radish sprouts and cattle feces. BMC Genomics. 2014;15:353.

90. Ercolini D, Ferrocino I, Nasi A, Ndagijimana M, Vernocchi P, La Storia A, et al. Monitoring of microbial metabolites and bacterial diversity in beef stored under different packaging conditions. Appl Environ Microbiol. 2011;77:7372-81.

91. Yang X. Microbial ecology of beef carcasses and beef products. In: de Souza Sant' Ana A, editor. Quant. Microbiol. Food Process. [Internet]. Chichester, UK: John Wiley \& Sons, Ltd; 2016. [cited 2017 Jun 9]. p. 442-62. Available from: http://doi.wiley.com/10.1002/9781118823071.ch22.

Submit your next manuscript to BioMed Central and we will help you at every step:

- We accept pre-submission inquiries

- Our selector tool helps you to find the most relevant journal

- We provide round the clock customer support

- Convenient online submission

- Thorough peer review

- Inclusion in PubMed and all major indexing services

- Maximum visibility for your research

Submit your manuscript at www.biomedcentral.com/submit
Biomed Central 